1

2

3

4

5

6

\title{
Uruk Expansion or Integrated Development? A Petrographic and Geochemical Perspective from Gurga Chiya, Iraqi Kurdistan.
}

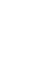

\author{
Michael P. Lewis ${ }^{a^{*}}$ Patrick S. Quinn ${ }^{b}$ Robert Carter ${ }^{c}$
}

\footnotetext{
${ }^{a}$ McDonald Institute of Archaeological Research. University of Cambridge. Downing Street CB2 3ER. United Kingdom.

${ }^{\mathrm{b}}$ Institute of Archaeology, University College London, 31-34 Gordon Square, London, WC1H 0PY, United Kingdom.

c University College London-Qatar, PO Box 25256, Georgetown Building, Education City, Doha, Qatar.
}

\section{*Corresponding author. Email address. m1830@cam.ac.uk}

\section{Key words.}

\author{
Late Chalcolithic \\ Uruk Expansion \\ Mesopotamia \\ Ceramics \\ Ceramic petrography \\ pXRF
}

\begin{abstract}
.
The Late Chalcolithic (LC; c.4500-3100BCE) was an important period in the developmental history of ancient Mesopotamia (modern Iraq, north-eastern Syria and south-eastern Turkey). New forms of sociopolitical and economic organisation are observed, characterised by household/settlement hierarchies, centralised production, craft specialization and redistribution. The Uruk Phenomenon of the latter 4th millennium BCE (LC3-5 in northern Mesopotamia and Middle-Late Uruk Period in southern Mesopotamia) coincides with the world's first urban societies in northern and southern Mesopotamia. This phenomenon includes the extension of long-distance trade and the spread of material culture (including pottery), architectural elements and administrative devices from southern Iraq across Mesopotamia. Nevertheless, the reasons for the spread of this material culture are a major point of contention in archaeological debate. Within this paper, we apply a combined quantitative and qualitative methods featuring macroscopic observations, ceramic petrography and pXRF to a selection of 38 pottery sherds from Gurga Chiya, a small site located within the Shahrizor Plain, Iraqi Kurdistan. Results demonstrate that the pottery analysed was all locally produced, perhaps at Gurga Chiya itself. Potential reasons for the transmission of the Uruk Phenomenon and its appearance at Gurga Chiya are discussed. We suggest that frequent, low-level contacts between Gurga Chiya and communities of the Shahrizor and adjacent regions as a prospective reason for the transmission of this cultural package into the region.
\end{abstract}

\section{Introduction.}

The 'Uruk Expansion' (Algaze 1989; 1993) is a major divisive (e.g. Stein 1999; Rothman 2001) cause of debate in Mesopotamian archaeology. Algaze $(1989,1993)$, applied a World Systems approach to 
explain the expansion. He argued the expansion was economic in nature through the establishment of colonies or enclaves set up by southern Mesopotamian city-states to syphon raw materials and elite goods. The acquisition of raw materials which were lacking in southern Mesopotamia was argued as a major motivation for this expansion by the emerging state and its urban 'core' of southern Iraq across huge swathes of northern Mesopotamia, deemed the 'periphery'. This expansion has been noted archaeologically via the spread of a distinctive suite of Uruk material culture including pottery, architectural elements and administrative devices. Elements of Uruk material culture are found across Mesopotamia, typically along trade routes, and at important nodes of communication (Algaze 2001: 47). However, the exact means by which elements of southern Uruk material culture came to be introduced to the north is still under debate. Theories include the physical movement of southern colonists to act as agents of trade and/or colonial control (Stein 2001), the activities of pastoral nomads (Abdi 2003; Porter 2012), the exploitation of agricultural land through the establishment of new settlements (Nissen 2001; Schwartz 2001), or even refugee movement (Johnson 1988-1989).

The nature of northern Mesopotamian communities as underdeveloped, passive partners to southern Mesopotamian urban states has been modified (Algaze 2005:138) due to excavations demonstrating a high degree of societal complexity (Frangipane 2016; 2018; McMahon 2015; Oates et al. 2007; alQuntar et al. 2011:153) and large scale urban centres in northern Mesopotamia prior to the interaction with the southern Mesopotamian 'core' (Ball et al. 1989: 32; Oates et al. 2007; al-Quntar et al. 2011). A more balanced (Algaze 2005: 147) or symbiotic relationship (Frangipane 2001; Stein 1999) between north and south Mesopotamia has also been proposed.

Current models to understand this period are driven by excavations in south-eastern Turkey and northeastern Syria (Frangipane 2018; McMahon 2015) where three broad categories of settlements feature Uruk material culture during the LC4/Middle Uruk. Colonies: newly established settlements with an identical material culture to southern Mesopotamia such as Qraya (Reimer 1988) or Sheikh Hassan (Boese 1995). Enclaves; foreign quarters of southern Mesopotamians within existing northern Mesopotamian settlements as exemplified by Hacinebi (Stein 2001) and Ramadi (Abu Jayyab et al. Forthcoming) with large enclaves at Nineveh (Gut 2002) and Tell Brak (Oates 2002). Additionally, local northern Mesopotamian sites with a local cultural assemblage include Leilan (Schwartz 1988). Finally, local settlements involved within a broader Uruk network featuring some degree of 'Uruk influence' including Feres al-Sharqi (Forest et al. 2012). Despite decades of academic debate, no single reason provides a clear answer for the spread of Uruk material culture. Does it involve the spread of Uruk colonists; an 'Uruk Expansion' into northern Mesopotamia, a cultural spread and gradual adoption of an Uruk habitus by local northern Mesopotamians, or something else entirely?

There requires therefore a new approach; one that considers the material culture as a regionalised assemblage (as per Trentin 1991: 8) and to investigate the repertoires from a regional perspective. Comparing these regionalised assemblages, it will then be possible to discuss the nature of the Uruk Phenomenon by piecing these small-scale studies together to construct a larger narrative.

The last decade has seen an influx of archaeological investigations into Iraqi Kurdistan (Altaweel and McMahon 2018), a comparatively unknown region archaeologically which has traditionally been framed as peripheral to the urban development of the southern Mesopotamian 'core'. This paper contributes to the discussion of the Uruk transmission into the Shahrizor by investigating the production of a sample of macroscopically southern Mesopotamian, Uruk pottery from Gurga Chiya, located in the Shahrizor Plain, using quantitative and qualitative analysis. The (semi)-quantitative data obtained here refers to the chemical composition of the samples within the study based on numerical pXRF data. Conversely, the qualitative data obtained refers to the qualities or characteristics of the samples. Through a combined approach, this study utilizes ceramic petrography, geological sampling and geochemistry in order to detect compositional patterns within the sampled ceramics of this site and identify provenance.

Ceramics from other northern Mesopotamia sites seldom featured within petrographic investigations, with no such studies undertaken to investigate LC ceramics from Iraqi Kurdistan. Where such studies 
were conducted, the results broadly indicate a lack of trade/exchange of pottery during the Uruk Period, indicative that another explanation for the transmission of the Uruk Phenomenon is likely (Eiland 2003; Fragnoli and Palmieri 2017). Nevertheless, some studies do indicate trade/exchange of specific ceramic form types: At Godin Tepe, evidence of trade/exchange of pottery vessels or their contents was noted. A wide variety of ceramic forms suggest probable imports from the neighbouring Zagros highlands, whilst limited, though important evidence of long-distance trade with Susiana was also observed from one nose-lugged vessel (Gopnik et al. 2016: 846). A similar situation was noted by Stephen and Peltenburg (2002) whereby a complex relationship between the sites of the Middle Euphrates was demonstrated via local and intra-regional trade/exchange of the vessels and their contents. A recent geochemical study demonstrated overwhelmingly local production of pottery during the LC in Mesopotamia, though with exceptional sites such as Nineveh which indicate the presence of moderate quantities of imported ceramics (Minc and Emberling 2016: 696). Clearly therefore, the dynamics of trade/exchange across the Uruk sphere varied enormously and, despite the extensive scale of Minc and Emberling's study, they were not able to analyse material from Iraqi Kurdistan. This leaves a considerable lacuna in our understanding of how this regionally diverse and complex area fits into broader narratives concerning the Uruk Phenomenon. This article will test the hypothesis that the ceramics from Gurga Chiya were manufactured locally. However, given that there has been no such analysis of the ceramics from Iraqi Kurdistan, this hypothesis is unknown and requires inquiry. The current study is therefore an important investigation to initiate discussion of the transmission of the Uruk Phenomenon into the Shahrizor and whether the current evidence suggests a physical expansion, or a more complex, integrated transmission.

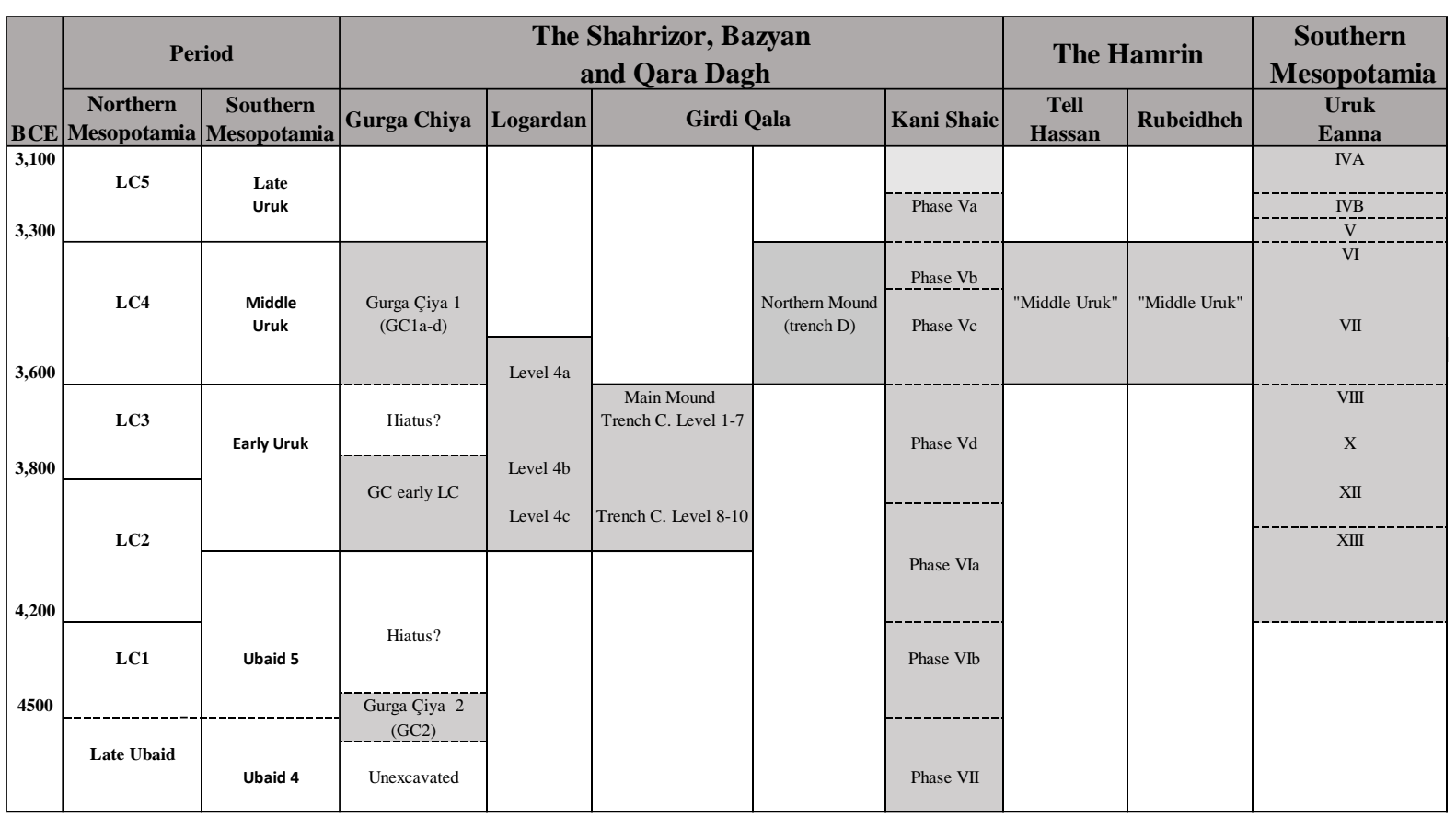

Insert Table 1 here 1.5 column fitting: Chronological chart showing the occupational phases of Gurga Chiya compared with selected sites mentioned in text.

\section{Gurga Chiya and its ceramic assemblage.}

Despite numerous excavations in the region, there are relatively few excavations which feature in-situ archaeological remains securely dated to the LC4/Middle Uruk (table 1). Gurga Chiya is an exception to this. Gurga Chiya is a small, one-hectare, multi-period site situated in the extreme south-east of the Shahrizor (figure 1), a wide alluvial plain covering an area of c.50x25km located in Sulaymaniyah Province, south-eastern Iraqi Kurdistan. Excavations since 2012 at Gurga Chiya have uncovered occupational levels dated to the Middle Uruk/LC4 featuring architectural remains and pyrotechnical 
installations. Also excavated was the combustion chamber of a pottery kiln and a dense deposit of macroscopically southern Mesopotamian, Uruk ceramics (fig 3) found together in the same stratigraphic level as one-another. The ceramics from this deposit are the subject of this investigation, though no sherds directly from the kiln feature within the present study (Carter et al. In press; Wengrow et al. 2016). Absolute dating of the LC4 phase at Gurga Chiya was confirmed through a radiocarbon date of 3640-3370 BCE cal. 2 sigma (Wengrow et al. 2016: 262). The Shahrizor is enclosed on all sides by mountain ranges with the Zagros foothills forming the northern and eastern extent and the Qara Dagh forming the southern border of the plain. Limited terrestrial passes ensure the plain was an important transit point between the southern Mesopotamia and the Iranian Plateau (Altaweel et al. 2012: 4).

Gurga Chiya is located within the Zagros Fold and Thrust Belt, a geological region composed of Triassic-Holocene marine-deposited sedimentary rock formations (figure 8) featuring limestone formations with occasional chert successions (Ali 2007: 79). The centre of the Shahrizor is marked by thick deposits of Holocene alluvial clay with common limestone and chert rock fragments eroded out of the surrounding mountains and geological formations (Ali 2007: 79-81).

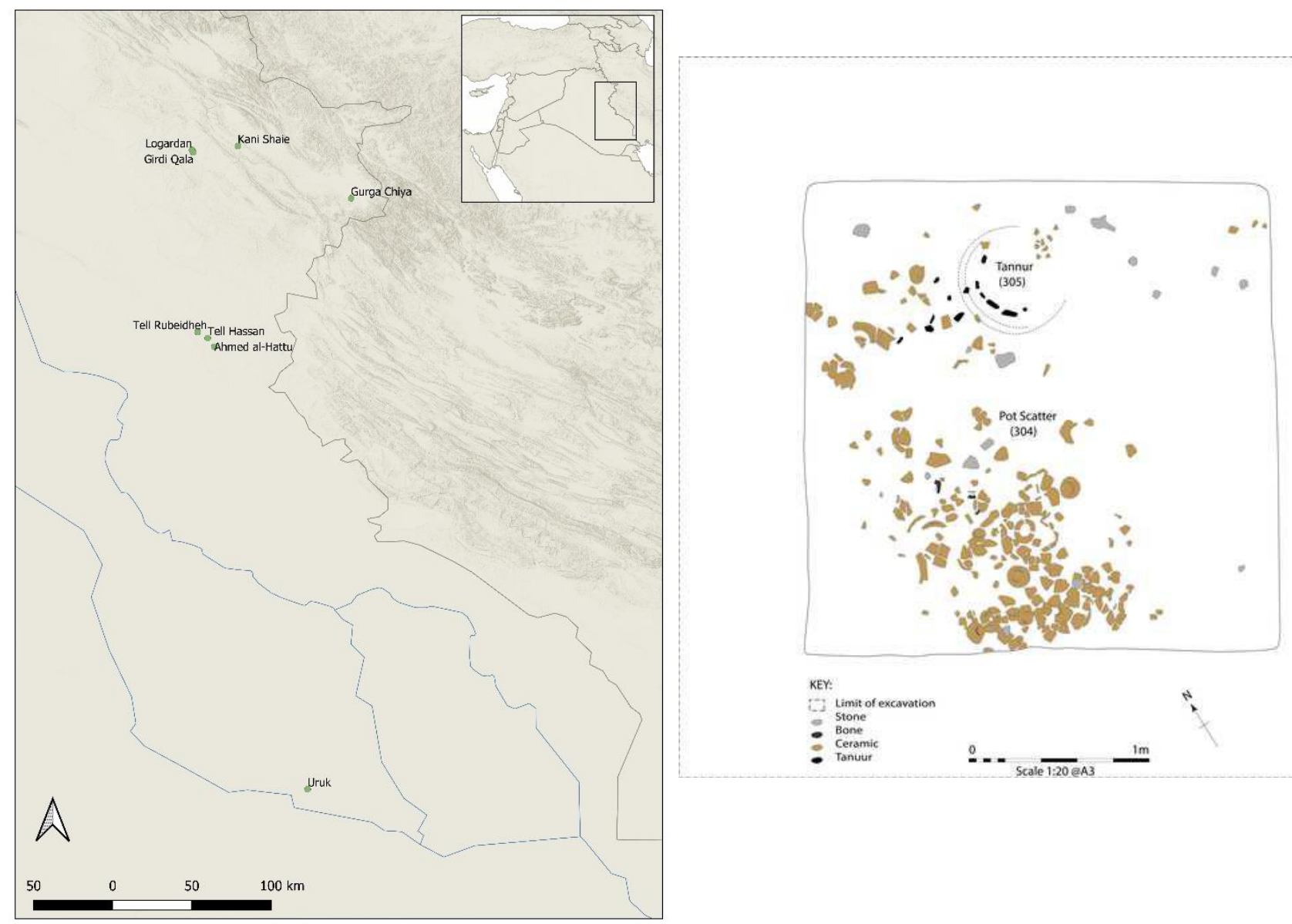

Insert Figure 1 here. 1.5 column fitting: Map showing the location of Gurga Chiya and selected key sites mentioned in the text. 
Uruk pottery is often seen as being largely uniform in appearance across much of ancient Mesopotamia and the sampled ceramics from Gurga Chiya largely adhere to this perceived uniformity. LC4 ceramic forms from Gurga Chiya (figure 3a-b) are generally comparable to those from other contemporary sites from Mesopotamia (Wengrow et al. 2016), though the most similar forms and ceramic assemblages are those found at sites in closest proximity to Gurga Chiya, centered upon north-central Iraq. Comparative forms are noted from Kani Shaie in the Bazyan Basin of Iraqi Kurdistan (Renette et al. In press; Tomé et al. 2016), as well as Tell Hassan (Nannucci 2012), Ahmed al-Hattu (Sürenhagen 1979) and Tell Rubeidheh (McAdam and Mynors 1988) in the Hamrin (figure 1).

All sherds in this analysis were selected from a single, secure context (context 304) characterised by an extensive pottery scatter dominated by macroscopically Uruk vessels. This context is not associated with any recognizable architecture and instead, features large quantities of pottery alongside poorly preserved faunal remains. The deposit is stratigraphically sandwiched between an oven layer above (GC-1a) with stone foundations for a wall below (GC-1c), all dated to the $\mathrm{LC} 4$ via relative dating. For this study, 38 sherds were sampled, corresponding to $9.4 \%$ of the total diagnostic sherd count from context 304 (table 2). A stratified sampling strategy was adopted based on ceramic macroscopic groupings initially sorted into ware group, and then form type. After sorting into ware groups, the ceramic was sorted into respective form types, and a representative sample of rim sherds were selected for sampling from each form type.

Within this analysis, sampled ceramics include characteristic southern Uruk pottery forms, several of which are new forms appearing within context 304: Sharply carinated (figure 3a.7) and slightly carinated bowls (figure 3a.5), grey burnished jars, sometimes with incised/applied rope cordons, nose lugged jars (Wengrow et al. 2016: fig 8.7), conical cups (fig 3a.1), sometimes with string-cut bases, squat jars with straight, cannon spouts (figure 3b.2; Wengrow et al. 2016: fig 8.9-10) and large jars with triangular profile rims, some featuring a thick, red slip (figure 3b.6). Other vessels are present within strata prior to context 304 including Bevelled Rim Bowls (BRB's; figure 3a.3-4), incurved rim bowls and everted rim grey ware jars (figure 3b.1,5,7).
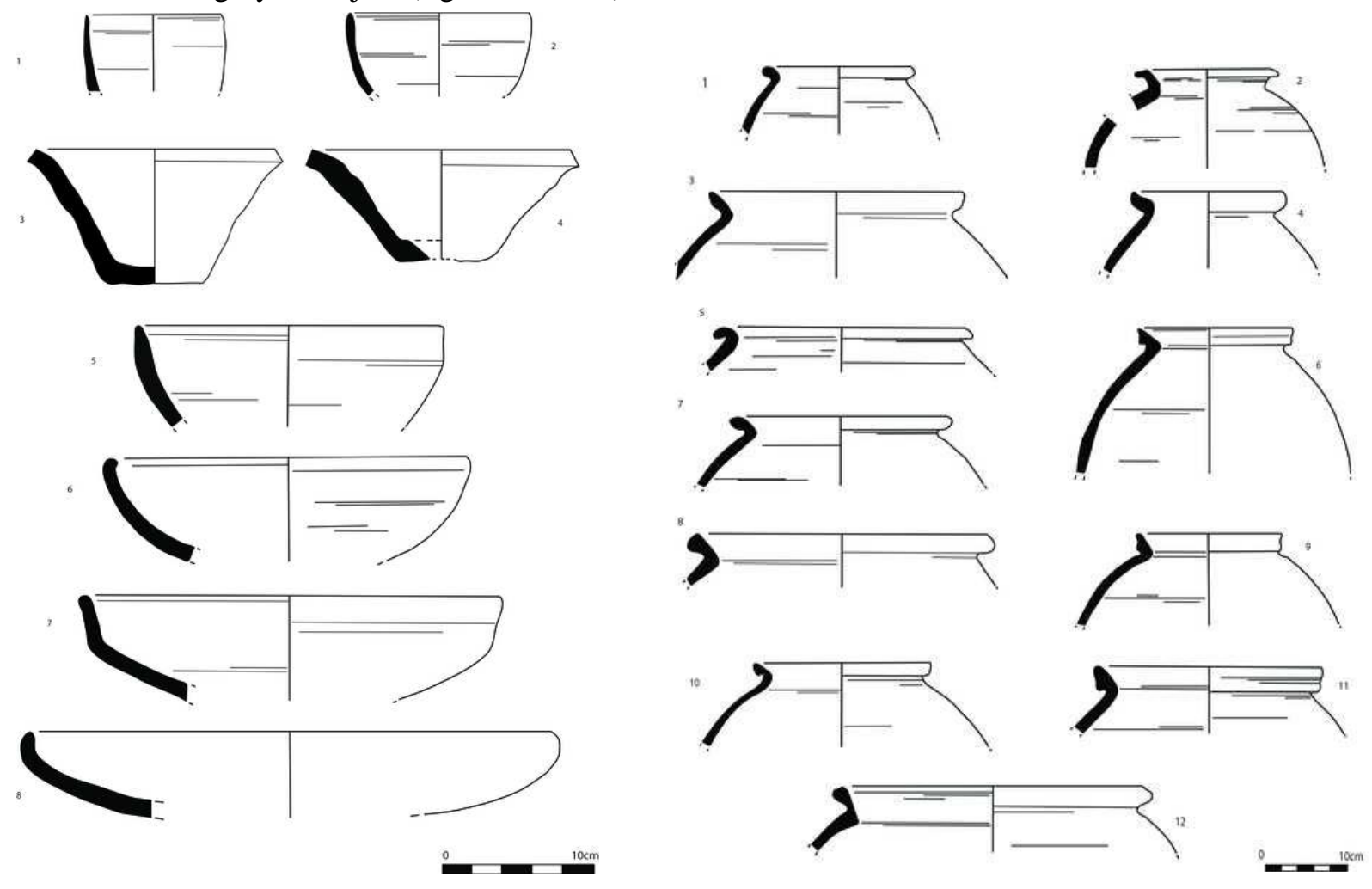
Insert Figure $3 a$ here $1 / 2$ column fitting (left): Selected LC4/Middle Uruk open pottery forms from Gurga Chiya sampled within the present study. Red Slipped Ware Group $(1,5,6,7,8)$. Cream Slipped Ware Group (2). BRB’s $(3,4)$.

Insert Figure $3 \mathrm{~b}$ here $1 / 2$ column fitting (right): Selected LC4/Middle Uruk open pottery forms from Gurga Chiya sampled within the present study. Fabric groups featured are Red Slipped Ware Group $(6,8,12)$. Grey Burnished Ware Group $(1,4,5,7,9,10,11)$. Fine Brown-Slipped Ware Group $(2,3)$.

3. Materials and Methods.

Sherds were initially sorted based on macroscopic observations, the nature and quantity of inclusions and ceramic form. The sherds were then characterized and classified in terms of their paste and composition using a combination of thin section ceramic petrography and geochemistry.

Vertical thin sections were taken from the rim of each sherd. Removed chips were prepared as per Quinn (2013: 21-33) and polished to 30 $\mu \mathrm{m}$ initially using a machine, and finally hand-polished using silicon carbide powder. Thin sections were examined using an Optical Petrographic Microscope with rotating stage under plane-polarized light (PPL) and crossed polars (XP).

Prior to thin sectioning, the 38 sherds were characterized chemically using a portable X-ray fluorescence (pXRF) spectrometer for bulk chemical ceramic composition, and to compliment the petrographic study to allow for geochemical as well as petrographic ceramic groupings. Problems are noted regarding the semi quantitative nature of pXRF (Forster et al. 2011), measuring elements with low/mid atomic numbers (Hunt and Speakman 2015: 4), or the difficulty in analysis of heterogeneous materials such as ceramics (Hunt and Speakman 2015; Tykot 2016). The sherds were analysed with an Innov_X Delta Premium device, using an in-house modification of the manufacturer's 'Soil' mode, calibrated with nine powdered geological reference materials (CRMs) certified for 30 major, minor and trace elements. This determines the concentration of $\mathrm{As}, \mathrm{Ag}, \mathrm{Au}, \mathrm{Ba}, \mathrm{Bi}, \mathrm{Ca}, \mathrm{Cd}, \mathrm{Ce}, \mathrm{Cl}, \mathrm{Co}, \mathrm{Cr}, \mathrm{Cu}$, $\mathrm{Fe}, \mathrm{Hg}, \mathrm{K}, \mathrm{La}, \mathrm{Mn}, \mathrm{Ni}, \mathrm{P}, \mathrm{Pb}, \mathrm{Rb}, \mathrm{S}, \mathrm{Sb}, \mathrm{Sn}, \mathrm{Sr}, \mathrm{Ti}, \mathrm{V}, \mathrm{Y}, \mathrm{Zn}$ and $\mathrm{Zr}$ using three beams (Beam $1-0.15$ mm Cu filter, 40kV; Beam 2 - 2 mm Al filter, $40 \mathrm{kV}$; Beam 3 - $0.1 \mathrm{~mm} \mathrm{Al} \mathrm{filter,} \mathrm{15kV).} \mathrm{Not} \mathrm{all} \mathrm{these}$ elements were used within the statistical analysis (see below; 1.3 Geochemical Results). These were set to record for 25, 25 and 50 seconds live time respectively, resulting in a real time of a few minutes per analysis. Three separate readings were taken for each sherd with an average reading used for the future statistical analysis. A calibration check was performed before each use and pXRF accuracy was calculated using five Certified Reference Materials before each use of the machine (JA-1, JG-1, JG-2 Geological Survey of Japan; NIST2702, NIST2781- National Institute of Standards and Technology). Three small areas on each sherd were abraded with a rotating diamond-tipped tool to remove any surface contaminants and provide a fresh spot for $\mathrm{pXRF}$ analysis.

To investigate the raw material sources and provenance of the ceramic samples of this study, as well as to gauge paste processing techniques, seven clay samples were collected from the alluvium of the southeastern Shahrizor (figure 8). A key aim was to collect clay samples from wadis from the different geological formations of the Shahrizor. Once collected, samples were dried before being manually crushed into a powder. The powder was sieved using a $2 \mathrm{~mm}$ mesh to remove larger mineral inclusions and plant matter. Water was added to the sieved powder and the mix formed into briquettes. Once died, the briquettes were fired at $750^{\circ} \mathrm{C}$ for 2 hours in an electric kiln. Thin sections were then produced from the briquettes using the same procedure as the archaeological thin sections.

\section{Results.}

\subsection{Macroscopic Results:}

Sampled vessels are characterised by a medium-grained fabric with frequent vegetal temper. A small quantity of open vessels show visible, white coloured mineral inclusions. The BRB's are the most 
abundant fabric/form and feature frequent, coarse vegetal temper which often have incompletely oxidised cores. Colour is often mid brown with a darkened mid-dark grey core. The Red Slipped ware group is the next most common fabric and features a mid-red fabric, often with a darkened mid to dark grey core and frequent vegetal inclusions alongside common, white, rounded mineral inclusions. Vessel surfaces regularly feature a thick, glossy red slip with occasional evidence of burnishing. The Grey Burnished ware group is dominated by globular jars, interpreted as cooking pots based upon the presence of angular mineral inclusions within the fabric. Vessel fabrics are dark grey with common angular white crystalline mineral inclusions and common vegetal temper. The exterior of these vessels are regularly slipped and burnished. Finally, the Cream-Slipped and Fine Brown-Slipped fabrics are both rare yet feature fine, pale brown fabrics with (respectively) cream and brown slips.

Macroscopic analysis confirms that BRB's are all manufactured in a mould, most likely an existing BRB whereby a slab of clay is pushed into an existing, fired BRB to form the desired shape (McAdam and Mynors 1988: 40; Renette et al. In press). The remainder of the sherds from Gurga Chiya depict evidence of manufacture via coiling, with vessel finishing on a rotary device or tournette. Conical cups with string-cut bases demonstrate clear evidence for horizontal rill-marks around the vessel and a characteristic, string-cut base, and are the only vessel type with clear evidence of manufacture on a fast wheel.

\subsection{Petrographic Results:}

The analysed ceramics can be sub-divided into six related petrographic fabrics in thin section. Fabrics are characterised by a calcareous clay matrix, often with common naturally occurring micritic limestone inclusions. The matrix of the petro-groups are very slightly optically active through to completely inactive. Several samples feature darkened mid-grey/black cores.

The majority of the analysed ceramics (63\%) belong to the Fine Vegetal Tempered Fabric (figure 4e) characterised by the addition of fine fragments of vegetal temper and a relative absence of mineral inclusions. The Micritic Limestone Fabric (figure 4a) is the next most common petro-group (13\%, $\mathrm{n}=6$ ) and features relatively common micritic limestone inclusions, quartz and rare muscovite, biotite and chert. Petrographic examination of contemporary, Uruk pottery from Tell Rubeidheh noted a very similar 'Medium Sand-Tempered' petro-group, comparative to the Micritic Limestone Fabric at Gurga Chiya. At Rubeidheh, it proved difficult to ascertain whether these petro-groups were tempered deliberately, or naturally sandy clays were exploited (Mynors 1988: 54). This same situation is noted with the Micritic Limestone Fabric at Gurga Chiya where a naturally sandy clay could have been used, conversely, sand temper may have also been deliberately added to the recipe. The Chert Fabric (figure 4b) $(8 \%, n=3)$ features frequent chert and common, naturally occurring micritic limestone. The Calcite Tempered Fabric $(8 \%, \mathrm{n}=3)$ is the only petro-group with the clear, deliberate addition of mineral temper and features angular calcite (figure 4d). The inclusions of this petro-fabric are bimodal on account of the large calcite temper grains and the finer intrinsic material. The Micritic Limestone and Chert Fabric $(5 \%, \mathrm{n}=2)$ features frequent micritic limestone, common chert, and frequent iron-rich mudstone (figure $4 c)$. It seems likely given the high frequency of micritic limestone compared with other petro-groups that this represents deliberate tempering of vessels, though these are restricted to closed jars, potentially cooking pots. Finally, the Oolitic Limestone Fabric (figure $4 \mathrm{f}$ ) is a single sample $(3 \%, \mathrm{n}=1)$ and is readily identifiable via its oolitic limestone inclusions.

There are several notable correlations between petrographic fabrics and macroscopic classification of the analysed sherds (table 2): The Red Slipped macro-group and the BRB's correspond well with the Fine Vegetal Tempered Fabric. The correlation of the fine fabrics with the BRB's seems striking given the visual coarse appearance of these vessels and their crude, roughly made appearance with a lack of surface treatment, especially compared with other forms from the Red Slipped macro-group. The Fine 
Cream Ware macro-group corresponds well with the Micritic Limestone Fabric; however there are only two samples of this fabric in the dataset. Furthermore, the Fine Brown Ware also correlates with the Fine Vegetal Tempered Fabric. Grey Burnished jars do not show any correlation with any specific petro-group (table 2). The petrographic analysis demonstrates that Grey Burnished jars were manufactured from any of four different petro-groups (Fine Vegetal Tempered abric, Micritic Limestone Fabric, Chert Fabric and Calcite Tempered Fabric.
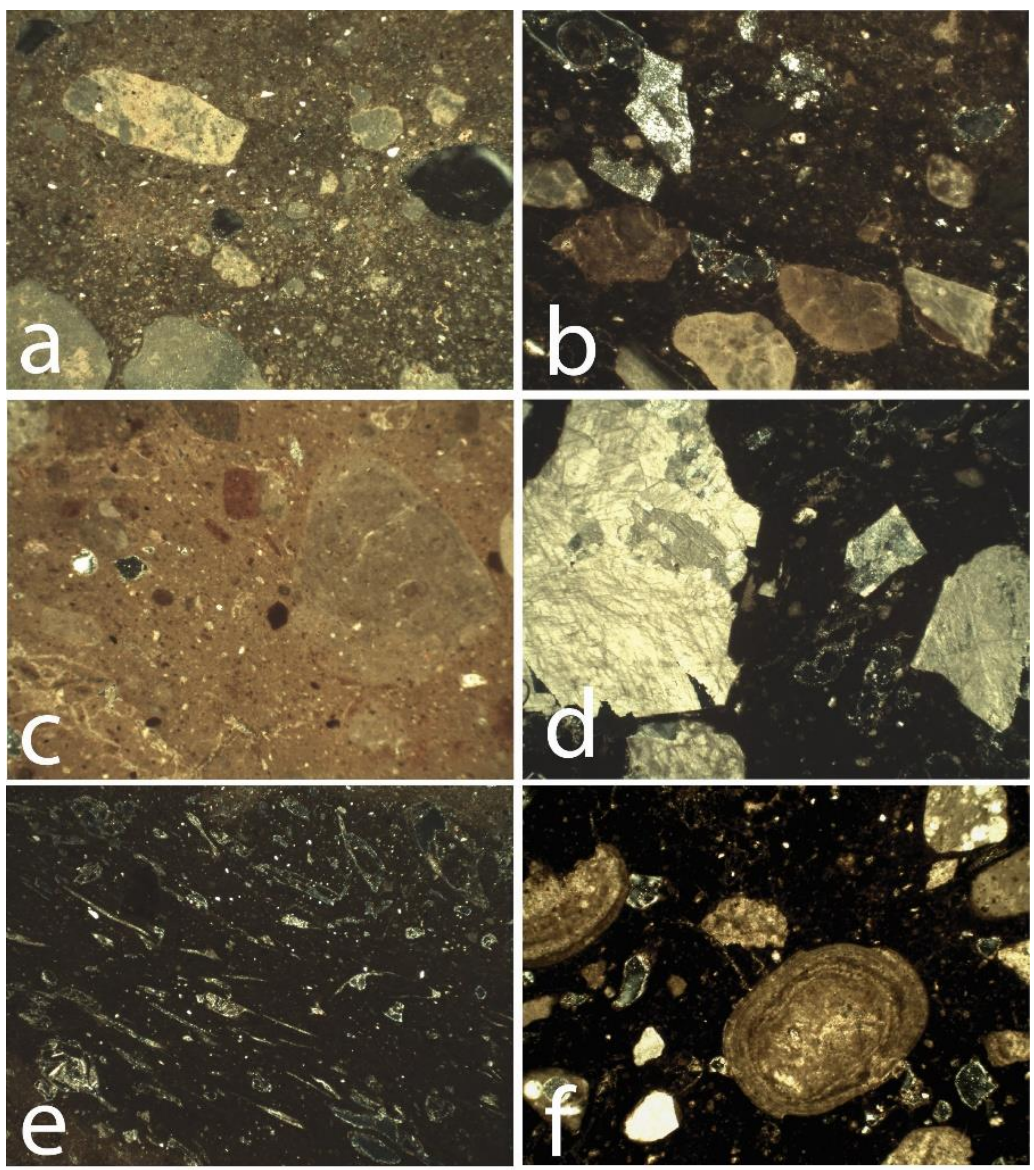

Insert Figure 4 here 2 column fitting image: Representative Photomicrographs of Petrographic Groups: a: Petro-Group 1: Micritic Limestone Fabric, XP GC13.304.168. b: Petro-Group 2: Chert Fabric, XP GC13.304.164. c: Petro-Group 3: Micritic Limestone and Chert Fabric, XP GC13.304.941. d: Petro-Group 4: Calcite Tempered Fabric, XP GC13.304.1097. e: PetroGroup 5: Fine Vegetal Tempered Fabric, XP GC13.304.942. f: Petro-Group 6: Oolitic and Micritic Limestone Fabric, XP GC13.304.170. All Images taken with Crossed Polars (XP) Image width of all photomicrographs=3.0mm. 


\begin{tabular}{|c|c|c|c|c|c|c|c|c|c|}
\hline $\begin{array}{c}\text { Sherd } \\
\text { No. }\end{array}$ & $\begin{array}{l}\text { Petro } \\
\text { Group }\end{array}$ & $\begin{array}{l}\text { Macroscopic } \\
\text { Ware Group } \\
\end{array}$ & Form & Open/Closed & Sherd No. & Petro Group & $\begin{array}{l}\text { Macroscopic } \\
\text { Ware Group } \\
\end{array}$ & Form & Open/Closed \\
\hline 164 & 2 & 21 (Uruk Grey) & UR100; Jar & Closed & 1074 & 1 & $\begin{array}{c}13 \text { (Uruk } \\
\text { Cream } \\
\text { Slipped) }\end{array}$ & UR14; Spouted Jar & Closed \\
\hline 165 & 5 & 15 (Uruk Red) & UR11; Jar & Closed & 1081 & 5 & 15 (Uruk Red) & UR4; Inverted rim bowl & Open \\
\hline 166 & 5 & 21 (Uruk Grey) & UR11; Cooking pot & Closed & 1082 & 5 & 15 (Uruk Red) & UR15; Jar & Closed \\
\hline 167 & 1 & 20 (Uruk Brown) & $\begin{array}{c}\text { UR14; Spouted } \\
\text { Jar }\end{array}$ & Closed & 1084 & 5 & 16 (Uruk Red) & UR14; Jar & Closed \\
\hline 168 & 1 & 15 (Uruk Red) & $\begin{array}{l}\text { UR6; Deep } \\
\text { bowl }\end{array}$ & Open & 1085 & 5 & 21 (Uruk Grey) & $\begin{array}{l}\text { UR11; Cooking } \\
\text { pot }\end{array}$ & Closed \\
\hline 169 & 5 & 15 (Uruk Red) & $\begin{array}{l}\text { UR5; Carinated } \\
\text { bowl }\end{array}$ & Open & 1094 & 4 & 21 (Uruk Grey) & UR9; Jar & Closed \\
\hline 170 & 6 & 21 (Uruk Grey) & $\begin{array}{l}\text { LC100; } \\
\text { Tray }\end{array}$ & Open & 1097 & 4 & 21 (Uruk Grey) & UR9; Jar & Closed \\
\hline 171 & 5 & 20 (Uruk Brown) & UR13; Jar & Closed & 1100 & 2 & 21 (Uruk Grey) & UR9; Jar & Closed \\
\hline 172 & 1 & 15 (Uruk Red) & UR4; Bowl & Open & 1101 & 2 & 21 (Uruk Grey) & UR9; Cooking pot & Closed \\
\hline 936 & 5 & 20 (Uruk Brown) & UR12; Jar & Closed & 1106 & 3 & 21 (Uruk Grey) & UR9; Jar & Closed \\
\hline 937 & 5 & 15 (Uruk Red) & UR100; Jar & Closed & 1110 & 5 & $\begin{array}{l}13 \text { (Uruk } \\
\text { Cream } \\
\text { slipped) }\end{array}$ & $\begin{array}{c}\text { UR2; } \\
\text { Tall Cup }\end{array}$ & Open \\
\hline 939 & 5 & 21 (Uruk Grey) & UR11; Cooking pot & Closed & 1112 & 5 & 15 (Uruk Red) & $\begin{array}{l}\text { UR3; Inverted rim } \\
\text { bowl }\end{array}$ & Open \\
\hline 940 & 1 & 15 (Uruk Red) & UR2; Tall cup & Open & 1115 & 5 & 15 (Uruk Red) & $\begin{array}{l}\text { UR3; Inverted rim } \\
\text { bowl }\end{array}$ & Open \\
\hline 941 & 3 & 20 (Uruk Brown) & UR100; Jar & Closed & 1118 & 5 & 200 (BRB) & UR1; BRB & Open \\
\hline 942 & 5 & 9 (Buff Incised) & LC1; Jar (Residual LC1 sherd) & Closed & 1122 & 5 & 200 (BRB) & UR1; BRB & Open \\
\hline 943 & 5 & 15 (Uruk Red) & UR15; Jar & Closed & 1123 & 5 & 200 (BRB) & UR1; BRB & Open \\
\hline 944 & 5 & 21 (Uruk Grey) & UR3; Inverted rim bowl & Open & 1127 & 5 & 200 (BRB) & UR1; BRB & Open \\
\hline 945 & 4 & 21 (Uruk Grey) & UR13; Cooking pot & Closed & 1128 & 5 & 200 (BRB) & UR1; BRB & Open \\
\hline 946 & 5 & 15 (Uruk Red) & UR3; Inverted rim bowl & Open & 1169 & 1 & $\begin{array}{l}13 \text { (Uruk } \\
\text { Cream } \\
\text { slipped) }\end{array}$ & UR3; Bowl & Open \\
\hline
\end{tabular}

Insert Table 2 here 1.5 column image: Sampled ceramics from context (304) analysed in this study noting petrographic groupings as well as macroscopic observations as observed in the field. Samples ordered via petro-group.

\subsection{Geochemical Results:}

Elements with poor accuracy (>30\%) were excluded from further statistical analysis, leaving nine elements for the present analysis $(\mathrm{K}, \mathrm{Ca}, \mathrm{Ti}, \mathrm{Cr}, \mathrm{Fe}, \mathrm{Ni}, \mathrm{Cu}, \mathrm{Zn}$ and $\mathrm{Pb}$ ). Two samples were excluded from the geochemical analysis (GC13.304.940 and 1110) because not all the elements were detected by the pXRF. Four further samples (GC13.304.937, 1081, 1106 and 1112) were also excluded owing to anomalous readings which strongly affected the average of the pXRF readings. This leaves a total of 32 sherds for statistical analysis presented below. The pXRF results were explored via multivariate statistics. The concentrations of the measured elements were log-transformed to base-10 logarithms and subjected to principal components analysis (PCA) and Hierarchical Cluster Analysis (HCA). Compositional patterning was then examined by plotting the first two principal components against each-other and investigating the elements that contribute most to the variability in the samples. The first two components of the PCA explained $66.1 \%$ of the total variance in the dataset and revealed the presence of a single geochemical group with two outliers (figure 7). One of these outliers in the top left of the scatter plot is explainable by the very high Ti content, whilst the other in the top left has highrelatively high readings of $\mathrm{K}, \mathrm{Fe}, \mathrm{Ni}, \mathrm{Ti}, \mathrm{Cu}$ and $\mathrm{Zn}$ alongside very low $\mathrm{Cr}$ and $\mathrm{Ca}$. It seems likely that this sherd is a residual sherd from the earlier LC1, and could be representative of a different, though similar clay used in its production. 


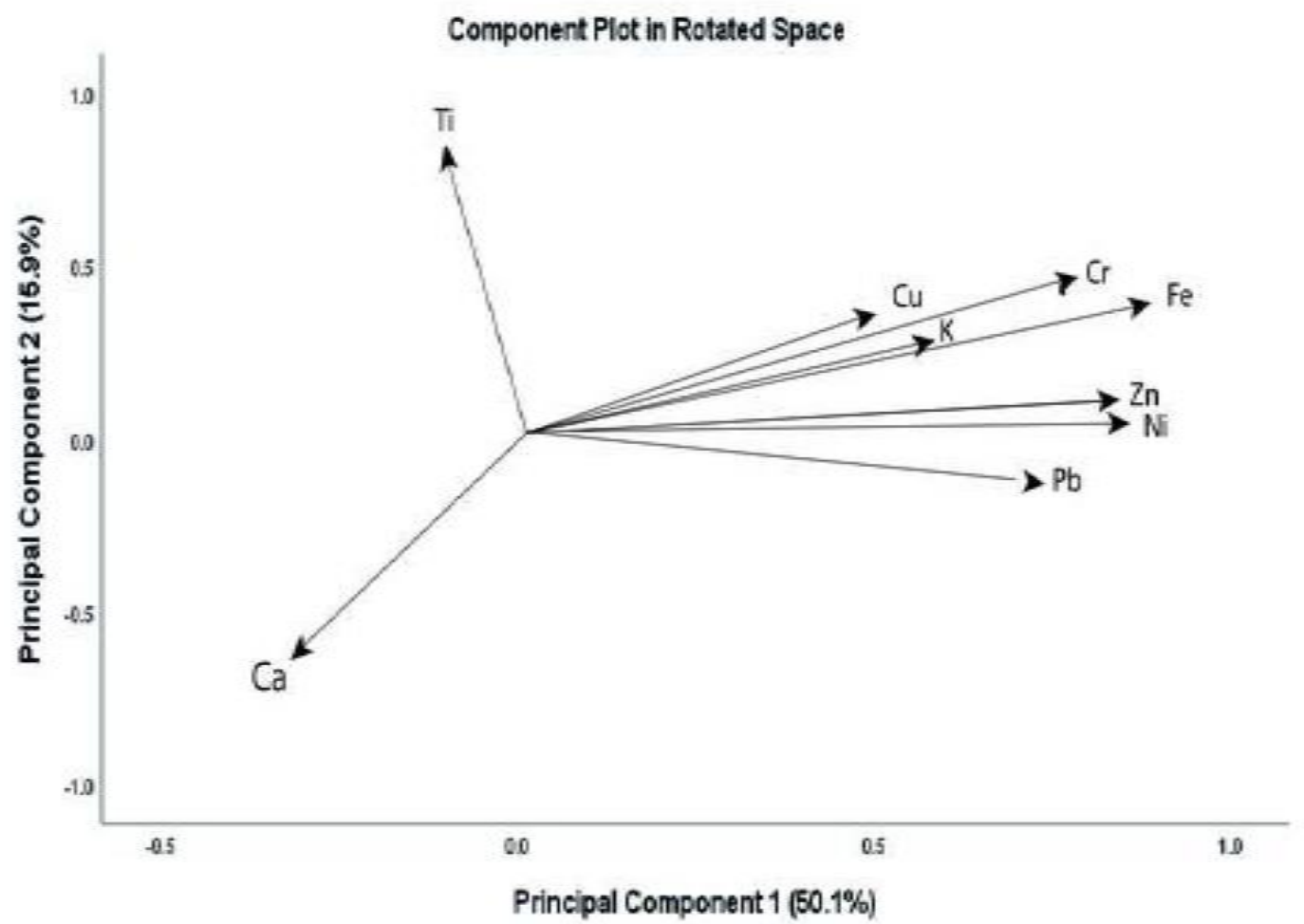

Insert Figure 5 here. $1 / 2$ column image: Factor Plot indicating the influence of the 9 measured elements on the first two Principal Components from the 32 analysed sherds of context (304) from Gurga Chiya. Log10 Transformed Data

The PCA scatter plots comparing principal components 1 and 2 demonstrated the presence of a single geochemical group with a small number of outliers. This single group is characterised by relatively high concentrations of $\mathrm{Fe}, \mathrm{Ni}, \mathrm{Zn}, \mathrm{Cr}, \mathrm{K}, \mathrm{Cu}$ and $\mathrm{Ti}$ compared to the small number of outliers. These data of these outliers were re-examined and demonstrated that a single anomalous pXRF reading of each caused a skewed average reading for statistical analysis.

a.

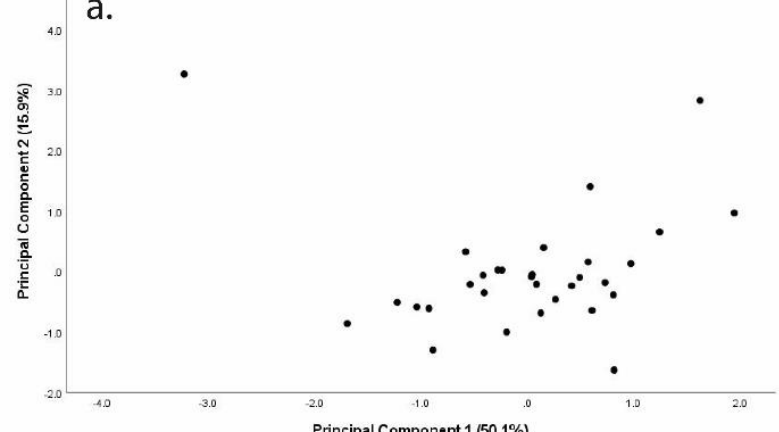

C.

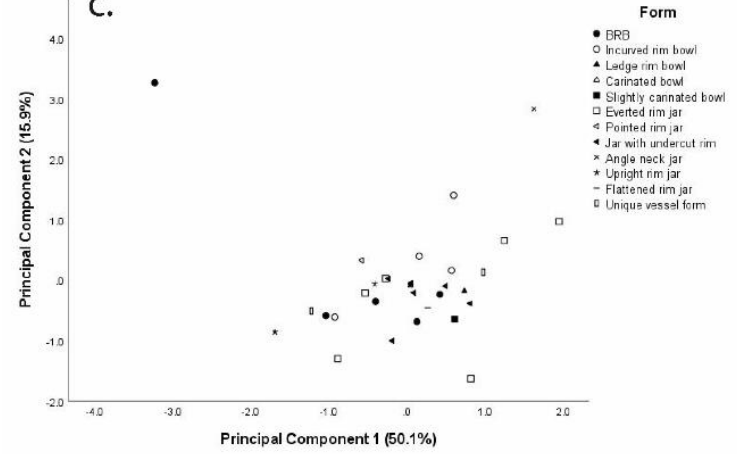

b.

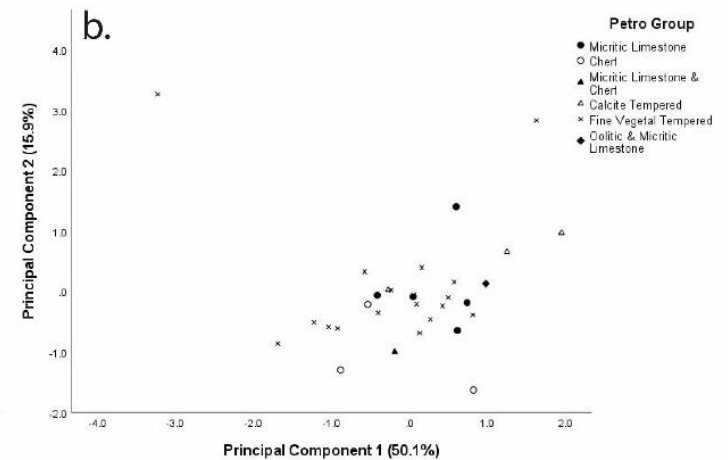

d.

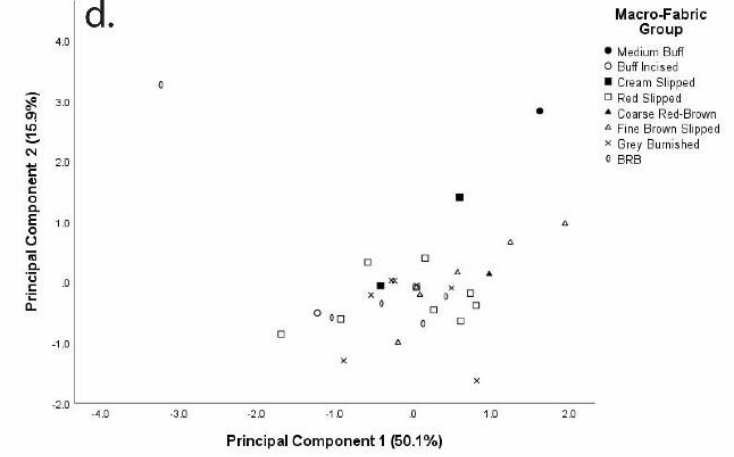


Insert Figure 6 here. 2 column fitting image: PCA of geochemical data collected via pXRF of the 32 LC4 sherds of context (304) from Gurga Chiya. a: Unlabeled scatter plot of scores for the first two Principal Components plotted against one-another. b: Scatter plot of scores for the first two Principal Components plotted against petrographic group. c: Scatter plot of scores for the first two Principal Components plotted against form. d: Scatter plot of scores for the first two Principal Components plotted against macroscopic grouping . Log10 Transformed Data, incl. Ca.

By labelling the samples in the plot according to their petrographic group (figure 6b), macroscopic form (figure 6c), and macroscopic fabric (figure 6d), there was no notable clustering of samples. The pXRF data was subjected to HCA using Ward's Linkage and squared Euclidean distance and plotted as a dendrogram (figure 7). Cluster analysis revealed the presence of two distinct clusters and a single outlier. Whilst the Fine Vegetal Tempered Fabric dominates the assemblage, and is thus found across the dendrogram's entirety, it is noteworthy that the remaining petro-groups are split decisively and broadly support the petrographic groupings: Excluding the Fine Vegetal Tempered Fabric, Dendrogram Group 1 contains all of the Chert Fabric and all but one of both the Micritic Limestone Fabric and the Chert Fabric. Dendrogram Group 2 is much smaller; however, features all but one of the Calcite Tempered Fabric. Reanalysis of the pXRF data shows that the major split in the dendrogram groups is caused by the relatively high-high concentrations of $\mathrm{Cu}, \mathrm{Ni}, \mathrm{Fe}, \mathrm{Cr}, \mathrm{T}$ and $\mathrm{K}$ in the samples within dendrogram group 2. Comparing the data from these samples with the petrographic slides, there is no immediate answer revealing their separation in the dendrogram, though some possible suggestions may be made. Sample 170 was subsequently confirmed to be an intrusive, earlier sherd from the Late UbaidLC1. This same reason can be applied to 1169. Regarding the remaining samples of dendrogram group 2 , they all come from long-lived pottery forms which are found from the earlier Late Ubaid/LC1 strata at Gurga Chiya and continue into the LC4/Middle Uruk. The vessels of Dendrogram group 2 include simple rimmed bowls (1169) and grey-ware everted rim jars $(171,945,1094)$. It is therefore likely that these are all residual, earlier sherds and a slightly different clay source was utilized in their manufacture, thus explaining the separation of these samples from dendrogram group 1. 


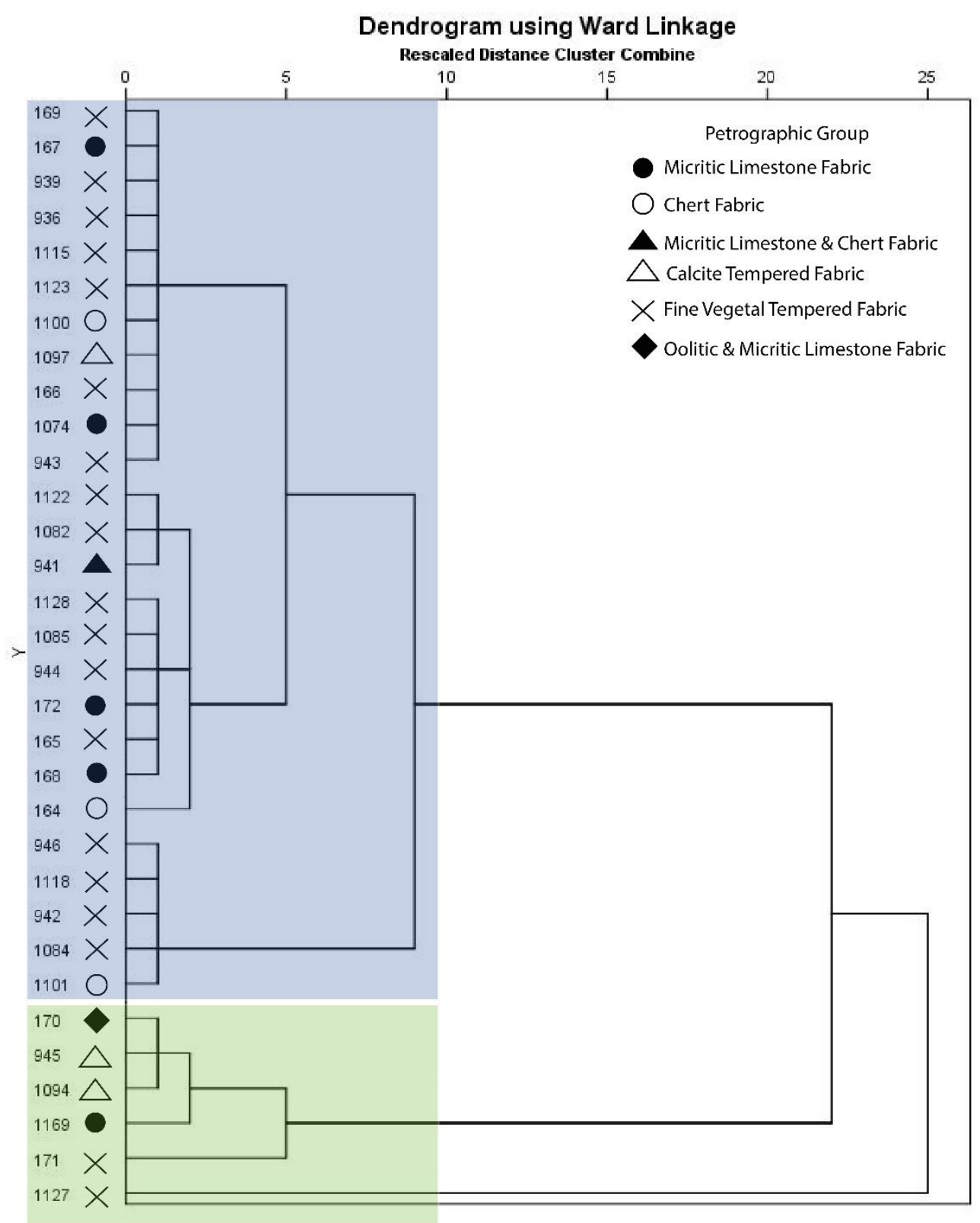

Insert Figure 7 here. 2 column image: HCA Dendrogram of Sampled Ceramics from Gurga Chiya, Context (304) showing the two dendrogram groups. Dendrogram Group 1 highlighted in blue, Dendrogram Group 2 highlighted in green. Sample Numbers of each sherd are shown on left. Log10 Transformed Data, incl. Ca.

1.4. Geological Sampling:

All geological samples (figure 8) appear compositionally very similar to the petrographic thin sections within this study. All geological thin sections have a highly calcareous matrix which ranges from middark brown to pale yellow-brown in colour. The mineral inclusions within the geological samples are all seen in the ceramic thin sections and include micritic limestone, chert, calcite, iron-rich mudstone and radiolarian chert. Overall, geological samples 1, 5, 6 and 7 demonstrate the closest petrographic match to the ceramic thin sections: all of which are the clay sources sampled in the immediate vicinity of Gurga Chiya, with samples 1 and 7 providing a very close match to the Fine Vegetal Tempered 


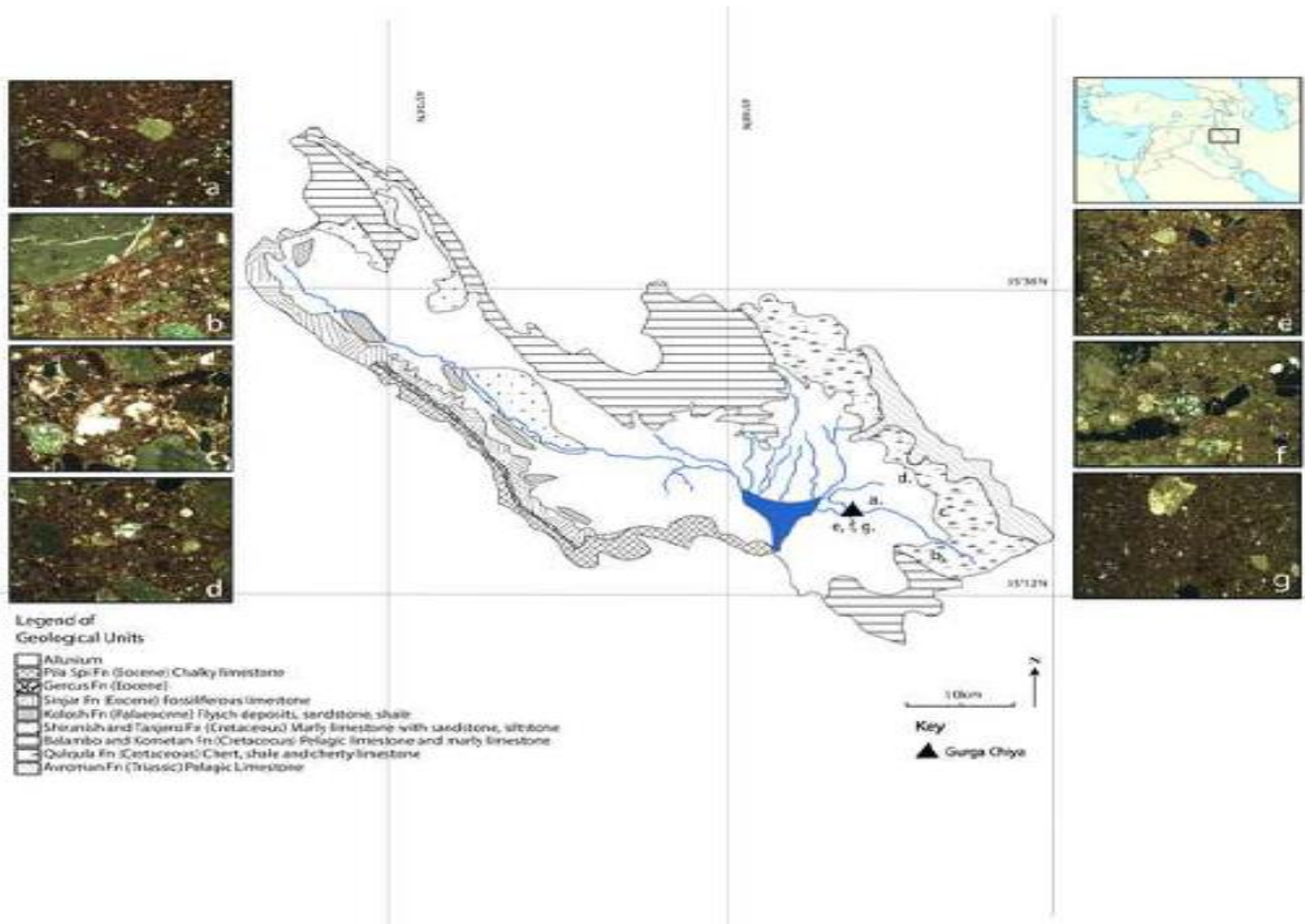

Insert Figure 8 here. 2 column image: Geological map of the Shahrizor-Pirmagroon Basin, with location and geological samples labelled. Map adapted after S.S Ali 2007. Photomicrographs of geological sample thin sections collected from the south-eastern Shahrizor. a. Geological Sample 1. b. Geological Sample 2. c. Geological Sample 3. d. Geological Sample 4. e. Geological Sample 5. f. Geological Sample 6 g. Geological Sample 7. All photomicrographs taken with Crossed Polars (XP) Image width of all $=3.0 \mathrm{~mm}$.

\section{Discussion: Uruk Expansion or Integrated Development?}

The analysis presented here indicates that the pottery which macroscopically resemble a suite of southern Mesopotamian vessels were all locally manufactured, arguably at Gurga Chiya. We claim this based upon the similarity of the petrographic and geological thin sections. This is further supported by the presence of a contemporary pottery kiln excavated within the same trench as the sampled ceramics There is no evidence of trade/exchange of the pottery within this study. These findings correlate with those from Minc and Emberling (2016) and their INAA results which overwhelmingly demonstrated local pottery manufacture. Through comparison of this data with geological maps of the Shahrizor (figure 8), we argue that potters exploited a secondary deposited clay source found near Gurga Chiya was exploited based upon the dominant mineral inclusions within the archaeological thin sections of micritic limestone and chert which are noted amongst the principal rock types surrounding the Shahrizor plain (Ali 2007: 73). Rock fragments were eroded from the mountains surrounding the Shahrizor, perhaps from the Qulqula Formation, a major geological formation featuring limestone and chert. Arguably, the chert and limestone fragments were then transported through the networks of waterways (Altaweel et al. 2012: Fig 2) into the alluvium of the Shahrizor, thus explaining their occurrence within the archaeological thin sections. Geochemical analysis demonstrates general homogeneity of clay recipe within the current dataset, and despite separation of the six petro-fabrics, it is clear that they are 
compositionally very similar, indicative that the ceramics within this study were manufactured using similar, though slightly different clay sources.

441 The presence of Middle Uruk/LC4 ceramics at Gurga Chiya has raised important issues concerning the nature of the Uruk Phenomenon in this part of Iraqi Kurdistan. Other Uruk (-related) settlements in the region are relatively uncommon with the nearest contemporary, Uruk (-related) settlement at Kani Shaie (Renette et al. In press; Tomé et al. 2016) and the Qara Dagh (Vallet et al. 2017; 2019). This is coupled with the complete absence of any direct evidence that long-distance exchange played any direct role in the transmission of ceramics/ceramic styles into the region. Rather, the evidence from Gurga Chiya suggests that Middle Uruk pottery was (re)created according to localised production methods. Trade was not likely a principle mechanism in the spread of Uruk material culture (such as pottery) into northern Mesopotamia (Frangipane 2018: 48), something which the present study confirms.

Shared archaeological traits including accounting and administrative devices, architectural elements and ceramic forms found across Mesopotamia during the Uruk Period have been highlighted as a result of expansionary socio-economic strategies of the southern Mesopotamian urban centres and elite driven trade and exchange (Algaze 1993). It is highly likely that economic considerations, especially trade/exchange featured as important themes within the consolidation of an elite ideology throughout the LC, including the Uruk Period (Frangipane 2018: 47). The rare occasions where pottery is shown to have been traded, the vessels are usually small closed jars which could have held precious commodities such as resins, perfumes or oils (Wright 2016: 902). Arguably this movement in luxury goods was to reaffirm the prestige of the elite and highlight their ability to control the flow of exotic materials. Such control of resources is exemplified by contents of the Riemchengebäude at the site of Uruk (Butterlin 2018: 349) whereby the elite restricted access to these goods by maintaining them within an elite realm.

The difficulty then, if trade/exchange does not explain the transmission of the Uruk Phenomenon into the Shahrizor, then what does explain it? An expansion related to the exchange of luxury goods or direct colonisation does not seem to be the case at Gurga Chiya. Only a relatively limited quantity of Uruk (related) material culture is known from the immediate vicinity (Renette et al. In press; Tomé et al. 2016; Vallet et al. 2017; 2019), and the archaeological excavations at Gurga Chiya have not revealed other material culture one would expect from an Uruk colony (architectural remains, administrative or accounting paraphernalia etc.). An unexcavated Uruk colonial emplacement may lie unexcavated somewhere within the Shahrizor, though this entirely speculative.

Reconstruction of the ceramic manufacturing process incorporating aspects of the chaine opératoire (Leroi-Gourhan 1964; Gosselain 2018; Roux 2019 etc.) alongside the Behavioral Chain (Schiffer 1972; 1976) by the lead author as part of ongoing PhD research demonstrates the LC4 pottery from Gurga Chiya was manufactured according to a local, pre-existing template. Ongoing excavations in the Qara Dagh (Vallet et al. 2017; 2019), c.100km west of Gurga Chiya have further highlighted the complexities regarding the Uruk transmission into the region: Here, a large complex of pottery kilns and Uruk monumental architecture has been excavated. Identification of different pottery manufacturing techniques strongly suggest the presence of a colony of Uruk residents at the site living alongside, though segregated from an existing northern Mesopotamian populace. It is the analysis of the ceramic chaîne opératoire that has led to such remarkable conclusions regarding the sites of the Qara Dagh and demonstrated that the production of Uruk and local pottery there follows divergent chaînes. Girdi Qala in the Qara Dagh features rapid settlement change during the LC3-4 : A newly established settlement founded at the northern mound features an overwhelming dominance of southern Uruk ceramics alongside architectural features, argued as the large-scale arrival of southern Mesopotamian immigrants (Vallet et al. 2019: 178). This is roughly contemporary to the Uruk (-related) pottery deposit and new suite of southern Uruk ceramics from Gurga Chiya and it may be that the two processes are (in)-directly linked. Gurga Chiya differs in that ongoing research into the chaîne opératoire indicates one 
predominant pottery forming technique used continuously from the Late Ubaid into the Middle Uruk/LC4 (Lewis 2017). Pottery within the current investigation was manufactured in accordance with the traditions already utilised within earlier, pre-Uruk phases of occupation at Gurga Chiya, the same technique which dominates the LC assemblage at Kani Shaie (Renette et al. In press). Previous cultural traditions were therefore maintained and expressed via continuity in primary forming techniques and the dominance of vegetal temper. The archaeological context at Gurga Chiya is very different. Here, the archaeology does not suggest a typical Uruk colony whereby we would expect a wider repertoire of Uruk material culture (architectural features and wall cones as observed in the Qara Dagh, as well as additional aspects; administrative technology, bullae, clay sickles) alongside ceramics. A far less formalised transmission of the Uruk Phenomenon into the Shahrizor therefore seems more likely, indeed, one which has been raised sees the Uruk Phenomenon emerge in the Shahrizor via alternative mechanisms to the traditional cultural-expansionary model, and instead was a largely independent extension of the activities already located in this region since the Late Ubaid (Carter et al. In Press).

Ethnographic and archaeological observations, namely frequent, low-level contacts provide fruitful avenues of discourse for explaining the Uruk transmission into the Shahrizor. The movement of potters was a key factor to account for the geographic transmission of knowledge (as per Gosselain 1998; 2011; Herbich and Dietler 1991). Ethnographically, marriage between different communities is often cited as an important aspect of the transmission of the potters and their skill set, with female potters moving from their place of birth to a new village and learning from their mother-in-law to show they are ready to integrate into their new family (Herbich and Dietler 1987). Similar examples of potters entering a new region with a recipe or even production technique deemed inappropriate will abandon that recipe to assimilate with their new environs through a redefinition of their identity (Gosselain 2011: 220-221). Gendered social arenas, indicative of intermarriage between local families and Mesopotamian males is a prominent thread within investigations at Hacinebi in south-eastern Anatolia where, in Middle Uruk domestic contexts, local cooking pots dominate the assemblage, not Uruk forms (Stein 2012: 144). Cooking is contended as a gendered, female-dominated activity (Graff and Rodríguez-Alegría 2012 and references therein) with pottery manufacture also a predominantly female-dominated task. It is concluded that Uruk males intermarried with local north Mesopotamian women at Hacinebi, thus accounting for the divergent ceramic forms (Stein 2012). Itinerant potters present another aspect of this low-level contact between communities of the LC are observed in both anthropology (Gosselain 2008: 165; 2015: 286) and archaeology: INAA of LC period clay ring-scrapers tools for pottery production from south-western Iran demonstrate that their composition differs to the local pottery and supports the notion of itinerant potters during the LC (Alden 2016).

The complexities in ethnographic examples highlight the difficulty in explaining the transmission of the Uruk Phenomenon into the Shahrizor. One scenario is that the Shahrizor acted as an appendage to central Iraq, particularly the Hamrin whereby we see similarly homogenising Uruk related developments occurring which are mirrored in Shahrizor. We believe the spread of Uruk (-related) material culture into the Shahrizor, and their appearance at Gurga Chiya are due to somewhat different social articulations than traditional modes would imply. Frequent, low-level contacts such as those listed above which existed between the different communities of the Shahrizor and settlement centres, conceivably even those of the Qara Dagh present a viable mechanism to explain the Uruk transmission here.

\section{Conclusion.}

By comparing the geological thin sections to the archaeological ones, and with the evidence from the geochemistry, it is strongly suggested that the pottery within this study was manufactured locally. The similarity of the geological samples to the archaeological ceramics is striking, and, alongside the 
presence of a suspected pottery kiln within the LC4 strata at Gurga Chiya strongly supports that the ceramics were manufactured at the site.

Six petrographic groups were identified within this investigation with the Fine Vegetal Tempered Fabric the most abundant of these. The absence of mineral temper corresponding with Uruk pottery forms has important ramifications for the identification of Uruk ceramics in adjacent regions. It indicates that the dichotomy of mineral tempered ceramics denoting Uruk pottery, and vegetal temper implying local pottery is too simplistic. Research at Girdi Qala and Logardan in the Qara Dagh features some mineral tempered, Uruk ceramics, yet the majority feature Uruk pottery with vegetal temper (Baldi 2017; Vallet et al. 2017), This scenario is further replicated at Kani Shaie whereby vegetal temper dominates the contemporary assemblage (Renette et al. In press).

Although the results of this study support the results obtained by Minc and Emberling (2016), the study is the first of its kind within the archaeology of the LC of Iraqi Kurdistan. This investigation has made important initial steps toward understanding the production of pottery at a small Middle Uruk/LC4 site in northern Mesopotamia, and initiated discussion to address the transmission of the Uruk Phenomenon into the Shahrizor by utilising a combination of quantitative and qualitative methods. We believe that the Uruk Phenomenon emerged in the Shahrizor through somewhat different social articulations than traditional models would imply, either expanding into the valley through frequent low-level contacts between the communities of the Shahrizor and adjacent regions, or as an alternative to the expansion model, developing simultaneously and in tandem with neighbouring regions through a continuous process of such small-scale interactions.

\section{Acknowledgments.}

This research was undertaken as part of the MSc dissertation of Michael Lewis and was conducted at the Institute of Archaeology, University College London. Thanks to Professor David Wengrow for his role as excavation co-director at Gurga Chiya as well as his support during my MSc. Thank you also to Professor Marcos Martinón-Torres as well as Agnese Benzonelli and Tom Gregory for their ongoing help throughout the MSc. A special thanks to excavation team at Gurga Chiya and Tepe Marani. My ongoing gratitude and thanks to colleagues and friends in the Sulaymaniyah Directorate of Antiquities, especially the Director, Kamal Rasheed for his ongoing support, as well as our museum representatives and colleagues Saber Ahmed Saber and Sami Jamil Hamarashi. Finally, we are grateful to the two anonymous reviewers for their comments and suggestions to improve our manuscript.

\section{Funding.}

This research did not receive any specific grant from funding agencies in the public, commercial, or not-for-profit sectors.

\section{References.}

Abdi, K. 2003. 'The Early Development of Pastoralism in the Central Zagros Mountains'. Journal of World Prehistory 17 (4): 395-448.

Abu Jayyab, K., Glasser, A., Albesso, M., Gibbon, E., Schwartz, I., Taraqji, A. and Razzaz, S. Forthcoming. 'Late Chalcolithic Occupation at Tell er-Ramadi (Syria): Results of 
the 2004-2006 Salvage Excavations'. Submitted to Paléorient.

Alden, J. R. and Minc, L. 2016. 'Itinerant Potters and the Transmission of Ceramic Technologies and Styles During the Proto-Elamite Period in Iran'. Journal of Archaeological Science; Reports 7. 863876.

Algaze, G. 1989. 'The Uruk Expansion: Cross-Cultural Exchange in the Early Mesopotamian Civilization'. Current Anthropology 30: 571-608.

Algaze, G. 1993. 'The Uruk World System'. University of Chicago Press. Chicago.

Algaze, G. 2005. 'The Uruk World System: The Dynamics of Expansion of Early Mesopotamian Civilization'. (2 $2^{\text {nd }}$ edn) University of Chicago Press. Chicago.

Ali, S. S. 2007. 'Geology and Hydrogeology of Sharazoor - Piramagroon Basin in Sulaimani Area, Northeastern Iraq'. Unpublished PhD dissertation. Submitted to the University of Belgrade. Belgrade.

al-Quntar, S., Khalidi, L. and Ur, J. 2011. 'Proto-Urbanism in the Late Fifth Millennium BC: Survey and Excavations at Khirbet Al-Fakhar (Hamoukar), Northeast Syria'. Paléorient 37 (2): 151-175.

Altaweel, M., Marsh, A., Müehl, S., Nieuwenhuyse, O., Radner, K., Rasheed, K. and Saber. S. A. 2012. 'New Investigations in the Environment, History, and Archaeology of The Iraqi Hilly Flanks: Shahrizor Survey Project 2009 - 2011'. Iraq 74: 1-35.

Altaweel, M. and McMahon, A. 2018. 'Recent Archaeology in Iraq'. Iraq 80: 263-266

Baldi, J. S. 2017. 'Chalcolithic Ceramics from Logardan Trenches D and E: Morpho-Stylistic Features and Regional Parallels'. In Vallet, R. (ed.). 'Report on the Third Season of Excavations at Girdi Qala and Logardan'. Institut Français du Proche-Orient : 57-66.

Ball W., Tucker D. and Wilkinson, T. J. 1989. 'The Tell al-Hawa Project. Archaeological Investigations in the North Jazira 1986-87'. Iraq 51: 1-66.

Boese, J. 1995. 'Ausgrabungen in Tell Sheikh Hassan. I, Vorläufige Berichte über die Grabungskampagnen 1984-1990 und 1992-1994' Schriften zur vorderasiatischen Archäologie. Bd. 5. Saarbrücker Druckerei und Verlag. Saarbrücken.

Butterlin, P. 2018. 'Architecture et Société au Proche-Orient Ancient. Les Bâtisseurs de Mémoire en Mésopotamie (7000-3000 av. J.-C.)’. Éditions A. \& J. Picard. Paris.

Carter, R., Wengrow, D., Shepperson, M., Roberts, K., Lewis, M. P., Marsh, A., Carretero, L. G., Sosnowska, H., D'Amico, A., Sagan, W. and Lockyear, K. 'The Later Prehistory of the Shahrizor Plain, Iraqi Kurdistan: Further Investigations at Gurga Chiya and Tepe Marani' Submitted to Iraq.

Eiland, M. 2003. 'Ceramics and Society'. In Matthews, R. (ed.). 'Excavations at Tell Brak: Volume 4. Exploring an Upper Mesopotamian Regional Centre, 1994-1996'. McDonald Institute Monographs. Cambridge: 321-362.

Forest J. D., Vallet R. and Baldi J. S. 2012. 'Tell Feres al Sharqi: A 5th-4th Millennium Site in the Khabur Drainage Basin. In: Matthews R. and Curtis J. (eds.). 'Proceedings of the 7th International Congress on the Archaeology of the Ancient Near East 12 April - 16 April 2010, the British Museum and UCL, London. Vol. 3, Fieldwork \& Recent Research.' Harrassowitz Verlag. Wiesbaden: 33-50.

Forster, N., Grave, P., Vickery, N. and Kealhofer, L. 'Non Destructive Analysis using pXRF: Methodology and Application to Archaeological Ceramics'. X-Ray Spectrometry 40 (5). 389-398 
Frangipane, M. 2001. 'Centralization Processes in Greater Mesopotamia: Uruk 'Expansion' as the Climax of Systemic Interactions among Areas of the Greater Mesopotamia Region'. In: Rothman, M. S. (ed.), 'Uruk Mesopotamia and Its Neighbours: Cross-Cultural Interactions and their Consequences in the Era of State Formation'. School of American Research Press, Santa Fe: 307-349.

Frangipane, M. 2016. 'The Development of Centralised Societies in Greater Mesopotamia and the Foundation of Economic Inequality'. In Meller, H., Hahn, H. P. Jung, R. and Risch, R. (eds.). 'Rich and Poor-Competing for Resources in Prehistoric Societies'. Tagungen des Landesmuseums fur Vorgeschichte. Halle: 469-489.

Frangipane, M. 2018. 'Different Trajectories in State Formation in Greater Mesopotamia: A View from Arslantepe (Turkey)'. Journal of Archaeological Research 26: 3-63.

Fragnoli, P. and Palmieri, M. 2017. 'Petrographic and Geochemical Investigations on the Pottery Production from Arslantepe-Malatya (Eastern Anatolia) From the Fourth to the Second Millennium BCE: Technological Continuity, Innovation and Cultural Change'. Archaeometry 59 (4): 612-641.

Gopnik, H. Reichel, C. Minc, L. and Elendari, E. 2016. 'A View from the East: The Godin VI Oval and the Uruk Sphere'. Journal of Archaeological Science: Reports 7: 835-848.

Gosselain, O. P. 1998. 'Social and Technical Identity in a Clay Crystal Ball'. In Stark, Miriam (ed.). 'The Archaeology of Social Boundaries'. The Smithsonian Institute Press. Washington, DC: 78-106.

Gosselain, O.P., 2008. Mother Bella was not a Bella. In Stark, M, T., Bowser B, J, and Horne, L (eds.). 'Cultural Transmission and Material Culture. Breaking Down Boundaries'. University of Arizona Press. Tucson. 150-177.

Gosselain, O. P. 2011. 'Fine if I Do, Fine if I Don't. Dynamics of Technical Knowledge in SubSaharan Africa'. In Roberts, B. W. and Vander Linden, M. (eds.). 'Investigating Archaeological Cultures: Material Culture, Variability, and Transmission'. Springer, New York: 211-227.

Gosselain, O. 2015. 'Roads, Markets, Migrants. The Historical Trajectory of a Male Hausa Pottery Tradition in southern Niger'. In Gauß, W., Klebinder-Gauß, G., von Rüden, C. (eds.). 'The Distribution of Technological Knowledge in the Production of Ancient Mediterranean Pottery, Vienna: 277-296.

Gosselain, O. 2018. 'Pottery Chaînes Opératoires as Historical Documents'. In Spear, T (ed.). 'Oxford Research Encyclopedia of African History'. Oxford University Press. Oxford. DOI:10.1093/acrefore/9780190277734.013.208

Graff, S, R and Rodríguez-Alegría, E (eds.). 2012. 'The Menial Art of Cooking. Archaeological Studies of Cooking and Food Preparation'. University Press o Colorado. Boulder.

Gut, R, V. 2002. 'The Significance of the Uruk Sequence at Nineveh'. In Postgate, J. N. (ed.).

'Artefacts of Complexity: Tracking the Uruk in the Near East'. British School of Archaeology in Iraq. Warminster: 17-48.

Herbich, I. and Dietler, M. 1991. 'Aspects of the Ceramic System of the Luo of Kenya'. Töpferei-und Keramikforschung, 2: 105-135.

Johnson, G. 1988-89. 'Late Uruk in Greater Mesopotamia: Expansion or Collapse? Origini 14: 595611.

Leroi-Gourhan, A. 1964. 'Le Geste et la Parole I- Technique et Langage'. Albin Michel. Paris. 
Lewis, M. 2017. 'Ceramic Production During the Late Chalcolithic at Gurga Chiya: A Petrographic and Geochemical Examination of Ceramics from the Shahrizor Plain, Iraqi-Kurdistan'. Unpublished

MSc thesis. Submitted to the Institute of Archaeology, University College London.

McAdam, E. and Mynors, H. S. 1988. 'Tell Rubeidheh. Pottery from the Uruk Mound'. In Killick, R. G. (ed.). 'Tell Rubeidheh: An Uruk Village in the Jebel Hamrin'. British Institute for the Study of Iraq. Warminster: 39-77.

McMahon, A. 2015. 'Tell Brak: Early Northern Mesopotamian Urbanism, Economic Complexity and Social Stress, Fifth - Fourth Millennia BC'. In McMahon, A. and Crawford, H. (eds.). 'Preludes to Urbanism: Studies in the Late Chalcolithic of Mesopotamia in Honour of Joan Oates'. McDonald Institute for Archaeological Research. Cambridge: 67-80.

Minc, L. and Emberling, G. 2016. 'Trade and Interaction during the Era of the Uruk Expansion: Recent Insights from Archaeometric Analyses' Journal of Archaeological Science: Reports 7: 793797.

Nannucci, S. 2012. 'La Ceramica dei Livelli Uruk di Tell Hassan, Hamrin' in Mazzoni, S. (ed.). 'Studi di Archeologiadel Vicino Oriente. Scritti Degli Allievi Forentini per Paolo Emilio Pecorella'. Firenze University Press. Firenze: 39-77.

Nissen, H. J. 2001. 'Cultural and Political Networks in the Ancient Near East during the Fourth and Third Millennia BC'. In: Rothman, M. S. (ed.), 'Uruk Mesopotamia and Its Neighbours: CrossCultural Interactions and Their Consequences in the Era of State Formation'. School of American Research Press. Santa Fe: 149-179.

Oates, J. 2002. 'Tell Brak: The $4^{\text {th }}$ Millennium Sequence and its Implications'. In Postgate, J. N. (ed.). 'Artefacts of Complexity: Tracking the Uruk in the Near East'. British School of Archaeology in Iraq. Warminster: 111-122.

Oates J., McMahon A., Karsgaard, P., al-Quntar S. and Ur, J. 2007. 'Early Mesopotamian Urbanism: A New View from the North', Antiquity 81: 585-600.

Porter, A. 2012 'Mobile Pastoralism and the Formation of Near Eastern Civilizations: Weaving Together Society'. Cambridge University Press. Cambridge.

Quinn, P. S. 2013. 'Ceramic Petrography: The Interpretation of Archaeological Pottery \& Related Artefacts in Thin Section'. Archaeopress. Oxford

Reimer, S. 1988 'Tell Qraya: A Summary of the 1984 Season'. Downloaded from https://www.terqa.org/EL-TQ/Reimer_1984_Tell_Qraya.pdf on 07.07.2020.

Renette, S., Abu Jayyab, K., Gibbon, E., Lewis, M., Abdulkarim Q, Z., Cabral, R. and Tomé, A.G. 'Late Chalcolithic Ceramic Development in Southern Iraqi Kurdistan: The Stratigraphic Sounding at Kani Shaie. Submitted to Iraq.

Rothman, M.S. 2001. 'The local and the regional: an introduction'. In: Rothman, M. S. (ed.), 'Uruk Mesopotamia and Its Neighbours: Cross-Cultural Interactions and Their Consequences in the Era of State Formation'. School of American Research Press. Santa Fe: 3-26.

Roux, V. 2019. 'Ceramics and Society: A Technological Approach to Archaeological Assemblages'. Springer. Cham. 
Schwartz, G. M. 2001. 'Syria and the Uruk Expansion'. In Rothman. M. S. (ed.). 'Uruk Mesopotamia and Its Neighbors: Cross-cultural Interactions in the Era of State Formation.' School of American Research Press: 233-265.

Schiffer, M. B. 1972. 'Archaeological Context and Systemic Context'. American Antiquity 37: 157165.

Schiffer, M. B. 1976. 'Behavioral Archaeology'. Academic Press, New York.

Schwartz, G. M. 1988. 'A Ceramic Chronology from Tell Leilan'. Yale University Press. New Haven.

Stein, G. J. 1999. 'Rethinking World-Systems: Diasporas, Colonies and Interaction in Uruk Mesopotamia'. University of Arizona Press. Arizona.

Stein, G. J. 2001. 'Indigenous Social Complexity at Hacinebi (Turkey) and the Organization of Uruk Colonial Contact'. In Rothman, M. S. (ed.) 'Uruk Mesopotamia and Its Neighbours: Cross-Cultural Interactions and their Consequences in the Era of State Formation'. School of American Research Press, Santa Fe: 265-305.

Stein, G, J. 2012. 'The Development of Indigenous Social Complexity in Late Chalcolithic Upper Mesopotamia in the 5th-4 ${ }^{\text {th }}$ Millennia BC - An Initial Assessment'. Origini XXXIV: 125-151.

Stephen, F. M. K. and Peltenburg, E. 2002. 'Scientific Analysis of Uruk Ceramics from Jerablus Tahtani and other Middle-Upper Euphrates Sites'. In Postgate, J. N. (ed.). 'Artefacts of Complexity: Tracking the Uruk in the Near East'. British School of Archaeology in Iraq. Warminster: 173-190.

Sürenhagen, D. 1979. 'Ahmad al-Hattu 1978'. Mitteilungen der Deutschen Orient-Gesellschaft 111: $35-50$.

Tomé, A., Cabral, R. and Renette, S. 2016. 'The Kani Shaie Archaeological Project' in K. Kopanias and J. MacGinnis, eds. 'The Archaeology of the Kurdistan Region of Iraq and Adjacent Regions'. Archaeopress. Oxford: 427-434.

Trentin, M. G. 1991. 'North-Western Uruk Period Pottery Assemblages'. Unpublished PhD thesis. Submitted to the Faculty of Arts of the University of London. London.

Tykot, R. H. 2016. 'Using Non Destructive Portable X-ray Fluorescence Spectrometers on Stone, Ceramics, Metals, and Other Materials in Museums: Advantages and Limitations'. Applied Spectroscopy 70 (1): 42-56.

Vallet, R., Baldi, J, S., Naccaro, H., Rasheed, K., Saber, S, A., and Hamarasheed S, J. 2017. 'New Evidence on Uruk Expansion in the Central Mesopotamian Zagros Piedmont'. Paléorient 43: 61-87.

Vallet, R., Baldi, J, S., Zingarello, M., Sauvage, M., Naccaro, N., Paladre, C., Bridey, F., Padovani, C., Rasheed, K., Raeuf, K., and Halkawt, Q. 2019. 'The Emergence of Cultural Identities and Territorial Policies in the Longue Durée: A view from the Zagros Piedmont'. Paléorient 45(2): 163 189.

Wengrow, D., Carter, R., Brereton, G., Shepperson, M., Hamarashi, S, J., Saber, S, A., Bevan, A., Fuller, D., Himmelman, H. and Sosnowska, H. 2016. 'Gurga Chiya and Tepe Marani: New Excavations in the Shahrizor Plain, Iraqi Kurdistan.' Iraq 76: 253-284.

Wright, H. T. 2016. 'The Uruk Expansion and Beyond: Archaeometric and Social Perspectives on Exchange in the IVth Millennium BCE'. Journal of Archaeological Science: Reports 7: 900-904. 
10. Appendix 1: Petrographic Fabric Descriptions

797

Petrographic Group 1: Micritic Limestone Fabric.
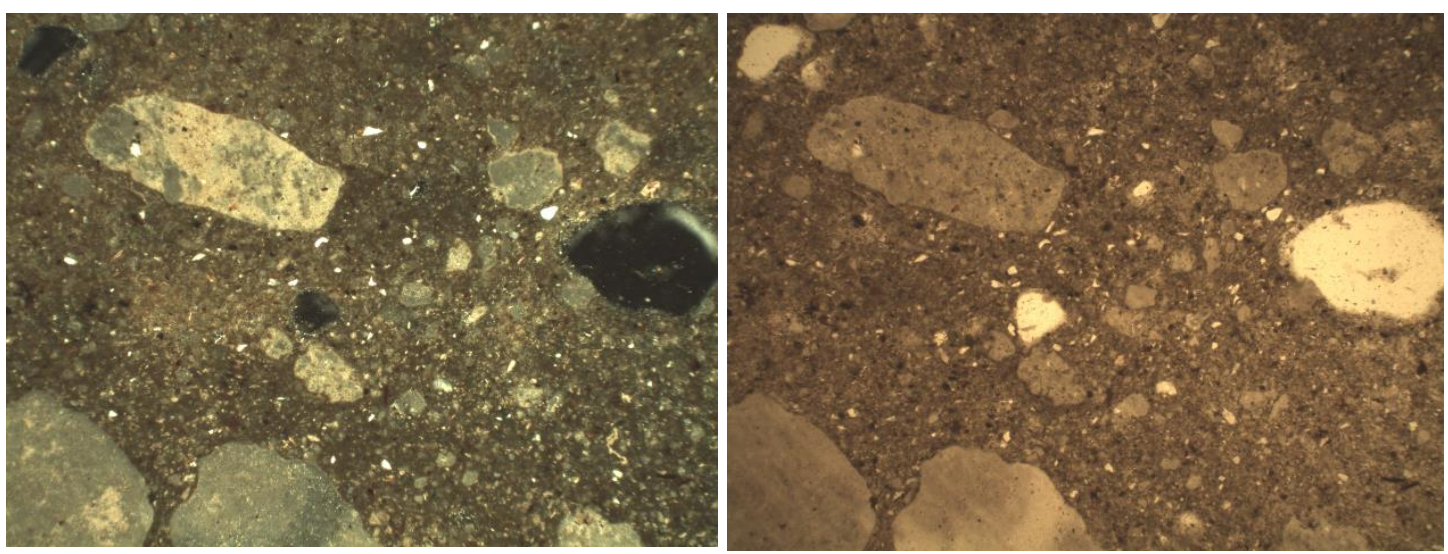

Photomicrograph of GC13.304.168: Left viewed in Crossed Polars (XP) and Right in plane, polarised light (PPL). Image width $3.0 \mathrm{~mm}$

807 Inclusions: 3\% single-double spaced. Moderate-strong alignment to margins of sample Unimodal. 808 Well sorted grain size distribution.

Dominant: Micritic Limestone. (Majority are $0.1 \mathrm{~mm}-0.4 \mathrm{~mm}$, though some thin sections have much larger, 1.0-1.6mm, micritic limestone inclusions such as GC13.304.168). Equant. Sub rounded-well rounded. Varying proportions of clay to foraminifera microfossils are noted; notable quantities of foraminifera microfossils are noted in some of the clasts, whilst absent from others resulting in differentiating colours ranging from green-brown through to opalescent. 
Rare. Muscovite. (0.04-0.2mm in length). Elongate. Angular. Bright inference colours in XP and colourless in PPL. Differentiated from Biotite as Biotite is brown in PPL. Parallel extinction.

Rare. Biotite. (0.04mm in length). Elongate. Angular. Brown/yellow in PPL. Pleochroism. Speckled, parallel extinction in XP.

819 Rare. Opaque Ironstone/Ferromagnesian Minerals. (most 0.04-0.08mm, although some much larger 0.16-0.2mm). Black in PPL, Black in XP. Equant-elongate. Sub rounded-sub angular.

Rare-Very Rare. Chert. (0.2-0.3mm) Equant-elongate. Angular-sub rounded. Black and white in colour (only noted in GC13.304.167).

Very Rare. Olivine. (0.04-0.08mm). Equant. Sub rounded. Pale green-grey in PPL, bright second order inference colours in XP.

Matrix: 95\%. Highly calcareous matrix. Mid orange-brown to mid grey-brown in colour throughout both core and margin. Very minor optical activity $(G C 13.304 .172,1169)$ to optically inactive (GC13.304.167, 168, 940, 1074).

Voids: 2\%. Meso-macro vughs and vesicles. Very few voids overall.

Comments: Highly fired, optically inactive

Petrographic Group 2: Chert/Grog Fabric.
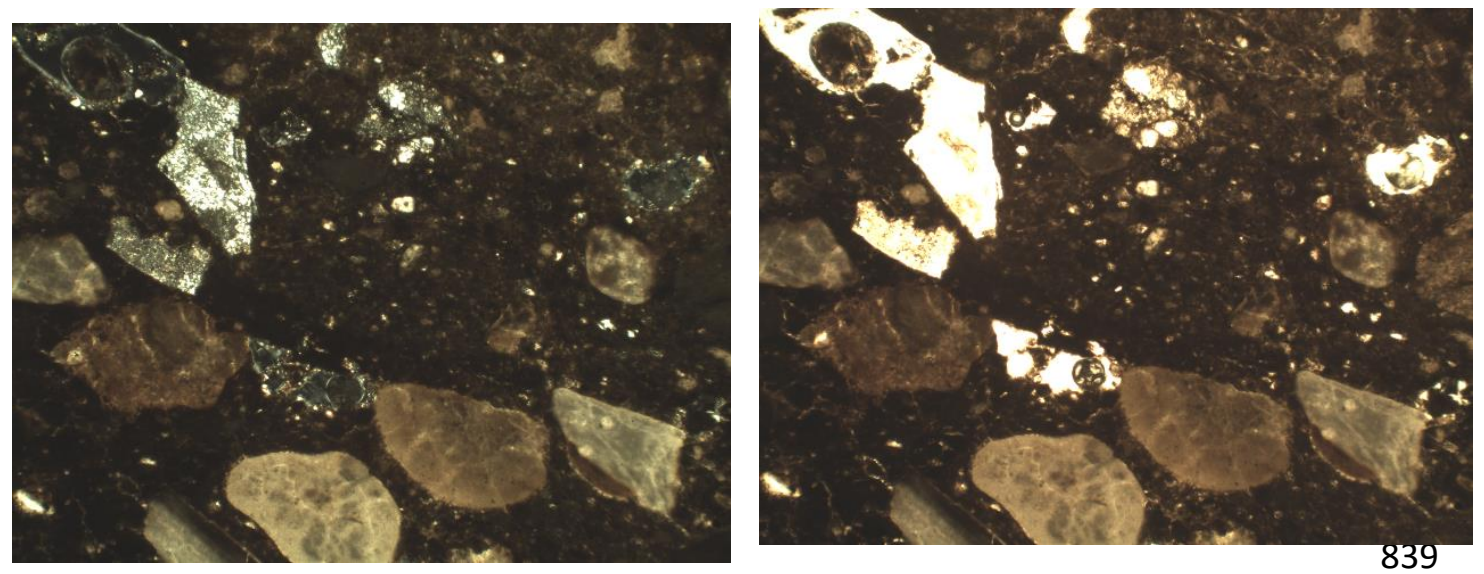

Photomicrograph of GC13.304.164: Left viewed in Crossed Polars (XP) and Right in plane, polarised light (PPL). Image width $3.0 \mathrm{~mm}$

Inclusions: 15\%. Equant and elongate. Rounded-sub angular. Single spaced or less. Moderate alignment to margins of samples. Unimodal, moderate-poorly sorted grain size distribution.

Dominant: Micritic Limestone. (most is large; $0.8-3.0 \mathrm{~mm}$ though lots of much smaller clasts $<0.1 \mathrm{~mm}$ in diameter) Usually green-grey but some mid brown in colour. Equant and elongate. Sub angularwell rounded. Varying proportions of clay to foraminifera microfossils are noted; notable quantities of foraminifera microfossils are noted in some of the clasts, whilst absent from others. 
Frequent: Chert $(0.6 \mathrm{~mm}-1.0 \mathrm{~mm})$ Equant-elongate. Angular-sub rounded. Majority of chert inclusions are black and white in colour, however a number show red/red-brown discolouration (GC13.304.1101).

Frequent: Calcite. (0.8-1.0mm) High birefringence. Equant-elongate. Sub angular-well rounded. Inclined extinction, multiple twinning and pastel colours in XP. Colourless, low relief in PPL showing clear cleavages at $120^{\circ}$.

Frequent. Quartz. (0.04-0.08mm) Equant. Angular-sub angular. White colour. Undulose extinction.

Rare. Mudstone (0.6-1.2mm in length). Equant-elongate. Sub rounded-rounded. Dark brown-black in $\mathrm{XP}$ and PPL. Bedding is noted in PPL.

Rare. Radiolarian Chert. (0.4-0.8mm in length). Equant-elongate. Sub angular-sub rounded. Noted in GC13.304.164, 1101. Black and white colour. Examples of clasts in GC13.304.1101 which are redbrown in addition indicating iron rich content.

Rare. Muscovite. Elongate (0.04-0.08mm in length). Elongate. Angular. Bright inference colours in $\mathrm{XP}$ and colourless in PPL. Differentiated from Biotite as Biotite is brown in PPL. Parallel extinction.

Rare. Biotite. (0.04mm in length) Elongate. Angular. Brown/yellow in PPL. Pleochroism. Speckled, parallel extinction in XP.

Rare: Oolitic Limestone. (1.0-2.0mm) Notable in GC13.304.164. Dark brown-grey in colour. The radial structure of the spherical ooliths are noted along with concentric laminations. Equant. Roundedsub rounded.

Very Rare. Grog. One huge example noted (macroscopically visible) in GC13.304.1100, along with smaller grog particles $(2.4 \times 1 \mathrm{~mm})$ throughout the thin section. The largest grog inclusion appears plant tempered with a notable high quantity of burnt out plant temper, characterised by meso-macro planar voids and channels. Also noted are equant, sub angular-sub rounded quartz inclusions $(<0.04 \mathrm{~mm})$. The boundaries of the grog are clearly defined, and especially clear in PPL. The matrix is dark brownblack throughout.

874 The smaller grog inclusion has micritic limestone $(0.2 \mathrm{~mm})$, equant and sub rounded, also quartz $875(<0.1 \mathrm{~mm})$, equant and sub-angular-sub rounded. The difference in inclusions could suggest that the 876 grog originates from different vessels.

877 Very Rare. Polycrystalline Quartz. (0.4mm). Equant. Sub angular-sub rounded. Only noted in 878 GC13.304.164.

879 Very Rare. Clinopyroxene $(<0.04 \mathrm{~mm})$. Equant, subhedral. Light brown in PPL. XP has bright inference colours with inclined extinction.

881 Matrix: Highly calcareous fabric. $80 \%$. Mid-grey brown to dark grey brown in colour. Optically inactive (GC13.304.164)-slightly active (GC13.304.1100). Core-margin differentiation (lighter, mid brown margin) noted in GC13.304.1100.

Voids: 5-10\% Mix of meso-elongate vughs (GC13.304.164) with moderate-poor alignment of voids to margins of section, but (GC13.304.1100) has meso-elongate planar voids and shows very strong alignment of voids to margins of section, (GC13.304.1100).

Comments: This fabric group is characterised by the presence of chert alongside other sedimentary rock types (present in the other fabric groups). The rounded nature of the micritic Limestone suggests it is not a deliberate addition to the matrix as a temper, but occurs naturally in the clay of the southeastern Shahrizor . The angular-sub-rounded chert seems to suggest otherwise, but as a harder rock 
then the mudstone/wackestone, it would be more resistant to erosion, and thus, more angular. Plant temper is likely an addition to the recipe in order to aid throw-ability of the vessel?

\section{Petrographic Group 3. Micritic Limestone and Chert Fabric.}
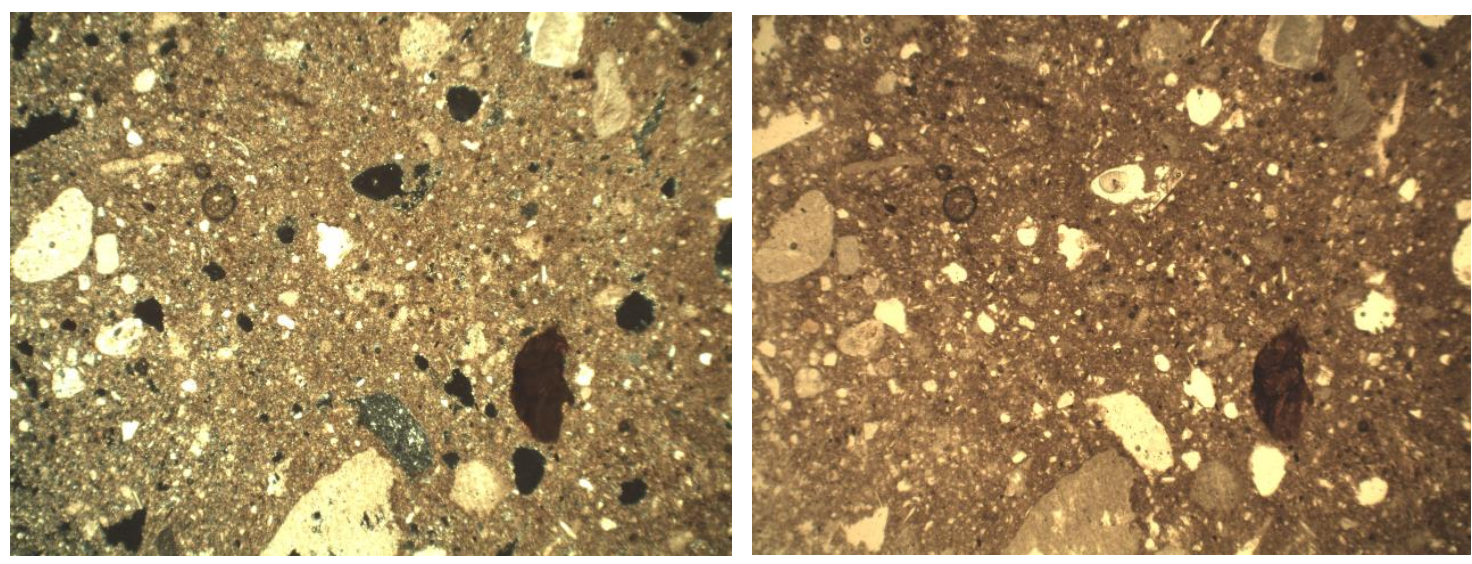

Photomicrograph of GC13.304.1106: Left viewed in Crossed Polars (XP) and Right in plane, polarised light (PPL). Image width $3.0 \mathrm{~mm}$

894

895

896

897

898

899

900

901

902

903

904

905

906

907

908

909

910

911

912

913

914

915

916

917

918

(Samples GC13.304. 941, 1106)

Inclusions: 5-10\%. Single-double spaced. Moderate-poor alignment to margins of sample. Unimodal. Moderately sorted grain size distribution.

Frequent: Micritic Limestone (0.6-1.0mm) (in GC13.304.1106), though some much larger inclusions (1x2mm in GC13.304.941). Equant-elongate. Rounded-sub rounded. Varying proportions of clay to foraminifera microfossils are noted; notable quantities of foraminifera microfossils are noted in some of the clasts, whilst absent from others resulting in differentiating colours ranging from green-brown through to opalescent.

Frequent. Iron rich mudstone. (0.6x0.4mm) (in GC13.304.941). Equant-elongate. Sub roundedrounded. Dark red brown-black in XP and PPL. Bedding is noted in PPL.

Common. Chert. (GC13.304.1106) (0.2-0.4mm) Equant-elongate. Sub rounded-well rounded. Black and white in colour. Larger inclusions $(0.8 \times 1 \mathrm{~mm})$ noted in $G C 13.304 .941$; also these are red in colour denoting iron-rich chert.

Few. Calcite. (0.1x0.3mm) High birefringence. Equant-elongate. Very angular (in GC13.304.1106) and rounded (in GC13.304.941). Inclined extinction, multiple twinning and pastel colours in XP. Colourless, low relief in PPL showing clear cleavages at $120^{\circ}$.

Rare. Quartz. (0.02x0.16mm) Equant. Angular-sub angular. White colour. Undulose extinction.

Very Rare. Muscovite. $(<0.01 \mathrm{mmx} 0.04 \mathrm{~mm})$ Elongate. Angular. Bright inference colours in XP and colourless in PPL. Differentiated from Biotite as Biotite is brown in PPL. Parallel extinction.

Very Rare. Biotite. ( $<0.01 \mathrm{mmx} 0.04 \mathrm{~mm})$. Equant. Angular. Brown/yellow in PPL. Pleochroism. Speckled, parallel extinction in XP.

Very Rare. Olivine. $(<0.1 \mathrm{~mm})$. Elongate-equant. Angular. Colourless in PPL, bright colours in XP. Zoning noted.

Very Rare: Chalcedonic Quartz $(0.2 \times 0.1 \mathrm{~mm})$. Equant. Sub angular-rounded. Black and white in colour. Radial appearance. 
Matrix: 90-95\%. Highly calcareous. Mid-dark brown through to pale yellow-brown. Optically inactive. Slight core-margin differentiation noted for GC13.304.1106 which has a dark brown margin with a lighter mid brown core.

Voids: $5-10 \%$. Meso vughs and micro-meso vesicles with occasional micro-macro planar voids and channels.

Petrographic Group 4. Calcite Tempered Fabric.
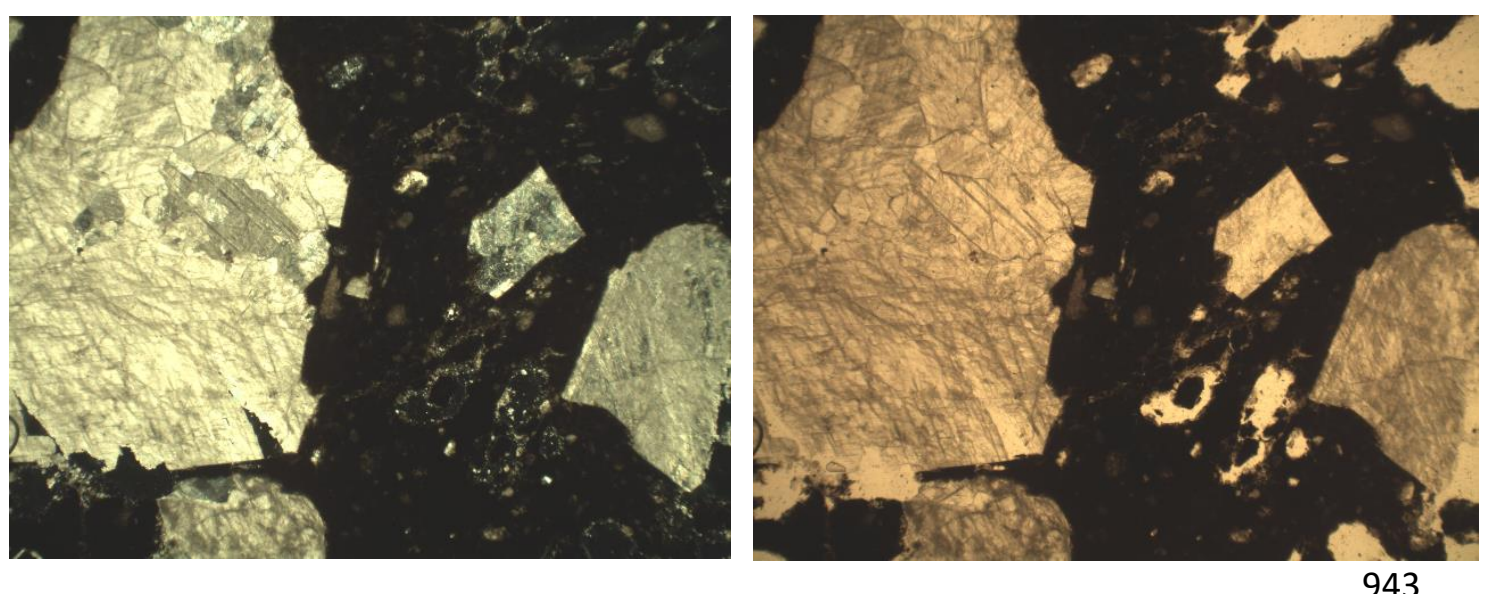

Photomicrograph of GC13.304.1097: Left viewed in Crossed Polars (XP) and Right in plane, polarised light (PPL). Image width $3.0 \mathrm{~mm}$

(Samples GC13.304.945, 1094, 1097)

Inclusions: 5-10\%. Single-double spaced. Moderate alignment to margins of sample (particularly GC13.304.945) Bimodal. Calcite is much larger than other inclusions, and is notably very angular. Poorly sorted grain size distribution.

Abundant: Calcite. (1.0x1.8mm, though some much larger-up to 3.4mm in length in GC13.304.1094) High birefringence, pastel colours. Equant-elongate. Very angular. Inclined extinction, multiple twinning and pastel colours in XP. Colourless, low relief in PPL showing clear cleavages at $120^{\circ}$.

Very Common. Micritic Limestone. (0.6-1.6mm). Equant-elongate. Rounded-sub rounded. Varying proportions of clay to foraminifera microfossils are noted; notable quantities of foraminifera 
microfossils are noted in some of the clasts, whilst absent from others resulting in differentiating colours ranging from green-brown through to opalescent.

Common. Quartz. (0.1 mm). Equant. Sub angular-rounded. White colour. Undulose extinction.

Very Few: Chert $(0.1 \times 0.2 \mathrm{~mm})$. Equant-elongate. Angular-sub angular. Black and white colouration.

Rare. Muscovite. $(0.04 \times 0.1 \mathrm{~mm})$ Elongate. Angular. Bright inference colours in XP and clear in PPL. Differentiated from Biotite as Biotite is brown in PPL.

Rare. Biotite. (0.06x0.02mm) Elongate. Angular. Brown/yellow in PPL. Pleochroism. Speckled, parallel extinction in XP.

Rare. Polycrystalline Quartz (0.06mm). Seen in GC13.304.1094. Equant. Sub angular-sub rounded.

Very Rare. Amphibole (Hornblende) (0.04-0.1 mm). Pleochroic with different shades of brown in PPL. Two intersecting cleavages noted at $120^{\circ}$. Only noted in GC13.304.1094.

Very Rare: Oolitic Limestone (0.8mmx0.8mm). Only noted in tiny quantities in GC13.304.1094. Dark brown-grey in colour. The radial structure of the spherical ooliths are noted, along with concentric laminations radiating around central calcite core. Equant. Rounded-sub rounded.

Very Rare. Plagioclase Feldspar. (0.02x0.04mm). Seen in GC13.304.1094. Colourless in PPL. Multiple twinning; black and white stripes noted in XP.

Very Rare. Opaque Ironstone/Ferromagnesian Minerals. (0.04x0.04mm). Black in PPL, Black in XP. Equant-elongate. Sub rounded-sub angular.

Very Rare. Clay pellets in 945 and 1097. (0.4x0.4mm and 1.0x1.8mm). Seen in GC13.304.945. Elongate. Sub angular-rounded. Dark brown in colour.

Matrix: Highly calcareous matrix. 85-90\%. Mid-dark brown to black-brown in colour. Very clear core-margin differentiation (lighter, red brown margins and dark brown core) noted in GC13.304.1094. Also clear core-exterior margin differentiation noted in GC13.304.945: yellowbrown exterior margin with mid-dark brown core. Minor optical activity $(G C 13.304 .945,1097)$, optically inactive (GC13.304.1094).

Voids: 5\%. GC13.304.945 dominated by meso-elongate planar voids with very strong alignment to margins of section. Also noted in this sample are macro vesicles and macro vughs. Within this sample, a very large quantity of the voids still contains carbonised (partial-fully) remains of chopped plant temper. GC13.304.1094 and 1097 dominated by meso-macro vughs and channels. GC13.304.1094 also has a moderate quantity of meso-elongate planar voids. Voids for GC13.304.1094 and 1097 are poorly aligned to the margins of the sample.

Comments: Similar to Fabric Group 2 although this Fabric Group differs due to the much higher quantity of calcite temper, and relative rarity of other mineral inclusions. The calcite is interpreted as deliberate temper added to the matrix owing to it being highly angular, and much larger than other mineral inclusions. It is important to note that this fabric group is the only one which features the identifiable, deliberate addition of mineral temper and corresponds to cooking pot vessels.

\section{Petrographic Group 5: Fine Vegetal Tempered Fabric.}



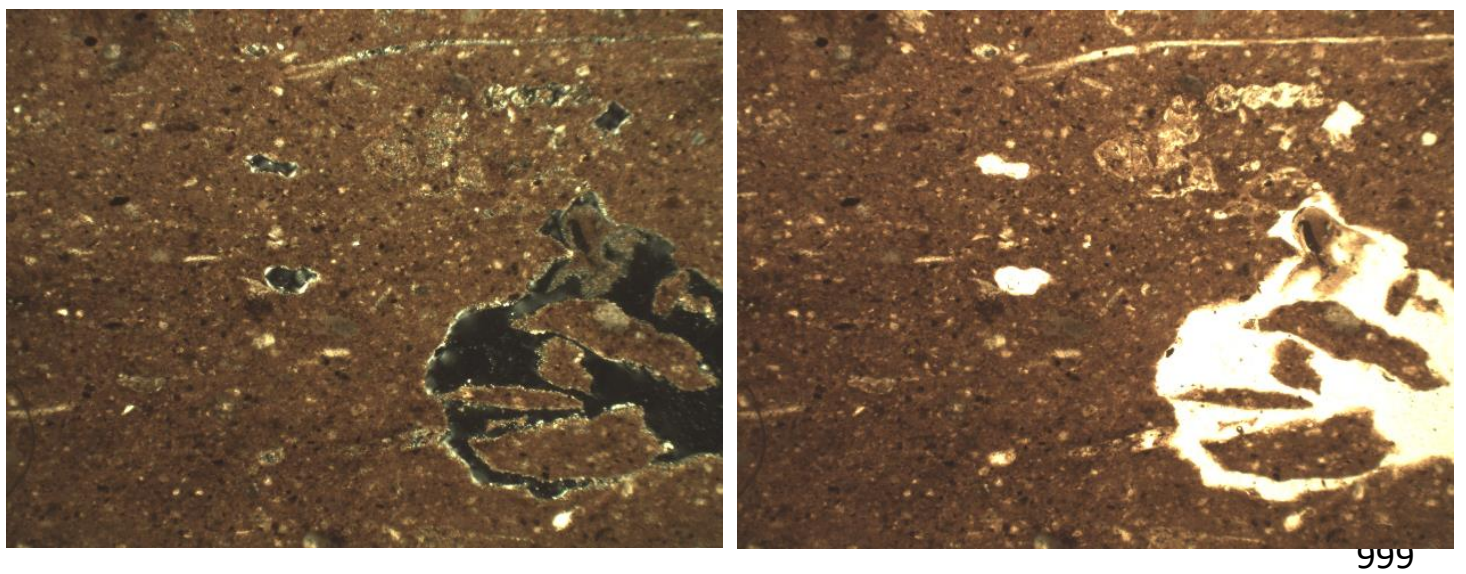

Photomicrograph of GC13.304.1081: Left viewed in Crossed Polars (XP) and Right in plane, polarised light (PPL). Image width $3.0 \mathrm{~mm}$

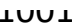

(Samples GC13.304.165, 166, 169, 171, 936, 937, 939, 942, 943, 944, 946, 1081, 1082, 1084, 1085, $1110,1112,1115,1118,1122,1123,1127,1128)$.

Inclusions: 3-5\% single-double spaced. Majority of the fabric group shows moderate-strong alignment of inclusions to the margins of the samples, although GC13.304.169 and 1112 show very poor alignment of inclusions. Unimodal. Most samples show well sorted grain size distribution, although GC13.304.946 shows solitary very large mineral (up to $2.0 \mathrm{~mm} \times 1.0 \mathrm{~mm}$ ) micritic limestone inclusions.

1009 Very few inclusions. Plant temper dominates this fabric group.

1010 Common. Micritic Limestone. (0.2-0.8mm, but some much larger inclusions $>2.5 \mathrm{~mm}$ such as 1011 GC13.304.171) Equant, sub rounded-rounded. Varying proportions of clay to foraminifera microfossils are noted; notable quantities of foraminifera microfossils are noted in some of the clasts, whilst absent from others resulting in differentiating colours ranging from green-brown through to opalescent.

Common. Chert. (0.1-0.3mm) Equant-elongate. Angular-well rounded. Black and white colouration.

Common. Quartz. (0.02-0.04mm). Equant. Angular-sub angular. White colour. Undulose extinction.

Rare. Muscovite. $(0.04 \mathrm{x} 0.1 \mathrm{~mm})$ Elongate. Angular. Bright inference colours in XP and clear in PPL. Differentiated from Biotite as Biotite is brown in PPL.

Few. Calcite (Large clast measuring 1.2x1.2mm in GC13.304.946, otherwise clasts are $<0.3 \mathrm{~mm}$ in size). High birefringence, pastel colours. Equant-elongate. Very angular. Inclined extinction, multiple twinning and pastel colours in XP. Colourless, low relief in PPL showing clear cleavages at $120^{\circ}$.

Rare. Biotite. (0.06x0.02mm, though few larger clasts $0.1 \times 0.15 \mathrm{~mm})$ Equant-Elongate. Angular. Brown/yellow in PPL. Pleochroism. Speckled, parallel extinction in XP.

Rare-Rare. Olivine. (0.04-0.08mm). Equant. Sub angular-sub rounded. Pale in PPL, bright second order inference colours in XP. Colourless in PPL, bright colours in XP. Zoning noted.

Rare. Radiolarian Chert. (0.4x1.0mm). Elongate. Sub angular-sub rounded. Noted in GC13.304.164, 946, 1122. Black and white colour.

Matrix: Highly calcareous matrix. 85-90\%. Minor optical activity. 12 of the thin sections show a very 

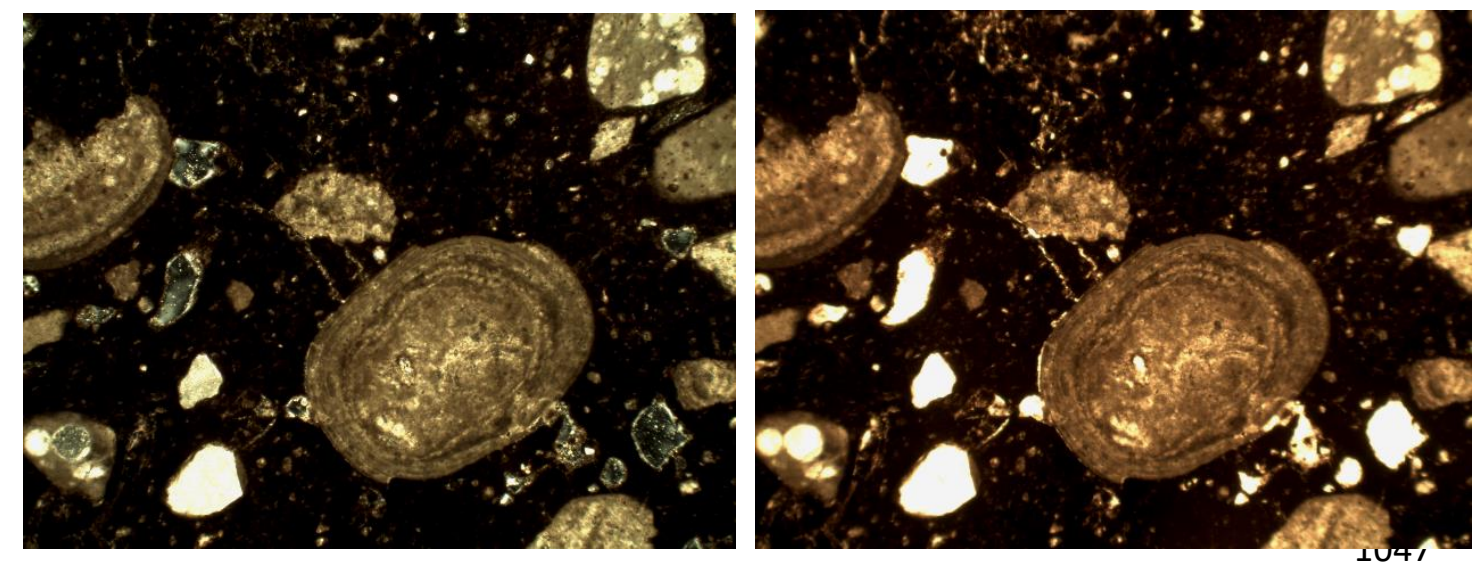

Photomicrograph of GC13.304.170: Left viewed in Crossed Polars (XP) and Right in plane, polarised light (PPL). Image width $3.0 \mathrm{~mm}$

(Sample GC13.304.170)

Inclusions: 5-7\%. Equant and elongate. Sub rounded-sub angular. Double spaced or less. Weak

through pale yellow brown, though the core of many of the thin sections are considerably darker black-brown (GC13.304.166, 171, 936, 939, 943, 944 1082, 1085.)

Voids: Meso-macro vughs, meso vesicules aligned strongly to the margins of the thin sections. Also elongate meso-micro planar voids. A number have secondary calcite deposited inside the voids $(G C 13.304 .1084,1115,1123)$, whilst $G C 13.304 .1112$ is interesting as areas around the voids are notably darker than the rest of the matrix, possibly caused during the firing whereby the carbonised plant temper burnt out? A number of examples also show clearly carbonised plant remains within the voids (GC13.304.166, 936, 939, 944, 1082, 1085).

\section{Petrographic Group 6: Oolitic and Micritic Limestone Fabric.} alignment to margins of samples. Unimodal, moderate-poorly sorted grain size distribution.

Abundant/Dominant: Micritic Limestone (Some relatively large clasts $1.2 \times 1.2 \mathrm{~mm}$, and some smaller $0.2 \times 0.25 \mathrm{~mm}$ ). Usually green-grey but some mid brown in colour. Equant and elongate. Sub angularwell rounded. Varying proportions of clay to foraminifera microfossils are noted; notable quantities of foraminifera microfossils are noted in some of the clasts, whilst absent from others resulting in differentiating colours ranging from green-brown through to opalescent.

Few: Oolitic Limestone. (1.0x1.2mm but some much smaller 0.2x0.2mm) Dark brown-grey in colour. The radial structure of the spherical ooliths are noted along with concentric laminations. Equant. Rounded-sub rounded.

Few-Rare: Calcite $(0.3 \times 0.2 \mathrm{~mm})$. Equant-elongate. Sub angular-very angular. Inclined extinction, multiple twinning and pastel colours in XP. High birefringence, pastel colours. Colourless, low relief in PPL showing clear cleavages at $120^{\circ}$.

Very Few-Rare: Shell. (0.8x0.1mm) Elongate. Angular. High birefringence, pastel colours. Colourless, low relief in PPL.

Very Few-Rare: Chert $(0.4 \mathrm{x} 0.6 \mathrm{~mm})$. Equant -elongate. Sub rounded. Black and white colour.

Rare. Muscovite. $(<0.04 \times 0.01 \mathrm{~mm})$ Elongate. Angular. Bright inference colours in XP and clear in PPL. Differentiated from Biotite as Biotite is brown in PPL. 
Rare: Quartz (0.04x0.04mm) Equant. Angular-sub angular. White colour. Undulose extinction.

1069

1070

1071

1072

1073

1074

1075

1076

1077

1078

1079

1080

1081

1082

1083

1084

1085

1086

1087

1088

1089

Rare: Opaque Ironstone/Ferromagnesian Minerals. (0.06x0.03mm). Black in PPL, Black in XP. Equant-elongate. Sub rounded-sub angular.

Very Rare. Olivine $(0.1 \mathrm{x} 0.1 \mathrm{~mm})$. Equant and angular. Pale in PPL, bright second order inference colours in XP. Colourless in PPL, bright colours in XP. Zoning noted.

Matrix: Calcareous matrix. 85\% Mid-brown to black-brown. Optically inactive. Core-margin differentiation (lighter, mid brown margin, black brown core) noted.

Voids: 5\%. Macro-mega vughs dominate the sample with a moderate quantity of meso-macro planar voids. Elongated vughs do show a moderate alignment to margins of sample section.

Comments: Single "loner" fabric group with only one sample. Similar to Fabric Group 2 (particularly GC13.304.1100), but for the absence of chert.

\section{Appendix 2: Geological Sampling. Fabric Descriptions Geological Sample a}
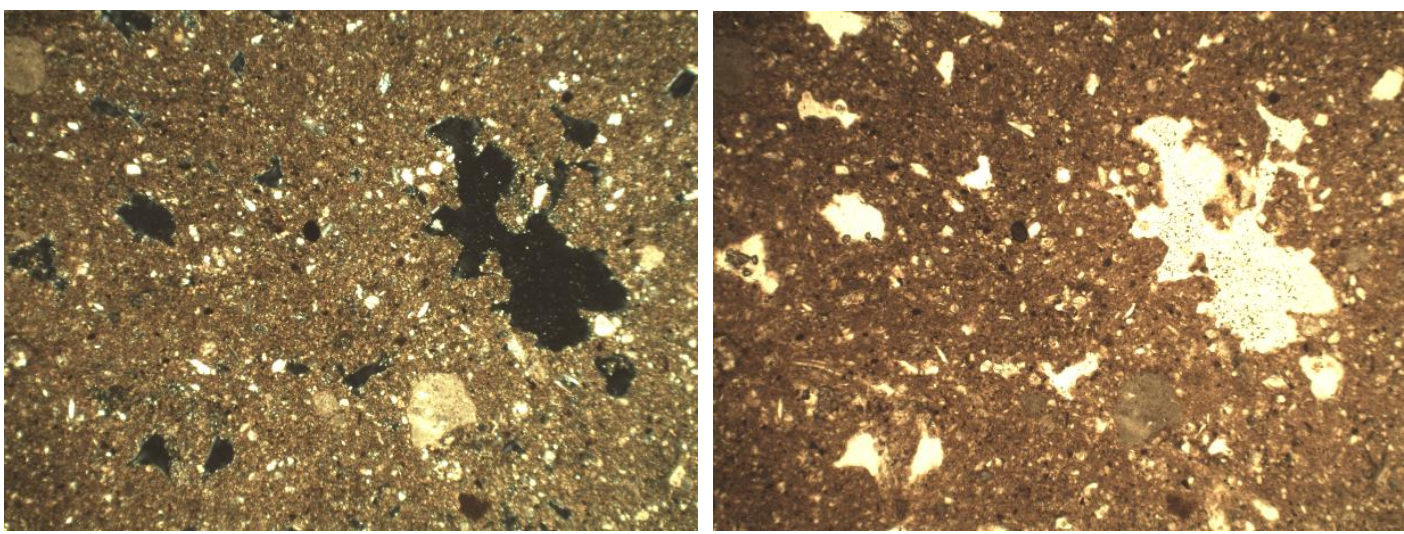

Photomicrograph of Geological Sample a: Left viewed in Crossed Polars (XP) and Right in plane, polarised light (PPL). Image width $3.0 \mathrm{~mm}$

Inclusions: $2 \%$ open spaced. No notable alignment to margins of sample. Unimodal. Well sorted grain size distribution.

Dominant: Micritic limestone $(0.04 \times 0.04 \mathrm{~mm})$ Equant. Sub angular-rounded. No foraminifera are noted in the clasts. Overall, the clasts are a pale-mid brown colour. 
Rare-Very Rare: Calcite. Equant. (0.04x0.04). Equant. (0.04x0.06mm) Very angular-angular. High birefringence, pastel colours. Equant-elongate. Very angular. Inclined extinction, multiple twinning and pastel colours in XP. Colourless, low relief in PPL showing clear cleavages at $120^{\circ}$.

Rare-Very Rare: Quartz. Equant. (0.02x0.02mm). Angular-sub angular. Undulose extinction.

Very Rare: Biotite. $(0.1 \mathrm{x} 0.1 \mathrm{~mm}$, though few larger clasts $0.1 \mathrm{x} 0.15 \mathrm{~mm})$ Equant-Elongate. Angular. Brown/yellow in PPL. Pleochroism., parallel extinction in XP.

Very Rare: Olivine. (0.01-0.01mm). Equant. Sub angular-sub rounded. Pale in PPL, bright second order inference colours in XP. Colourless in PPL, bright colours in XP. Zoning noted.

Very Rare: Chert. Elongate. (0.12x0.02mm). Sub angular-sub rounded. Black and white colour.

Very Rare: Radiolarian Chert. 0.01x0.01. Equant. Angular-sub angular. Black and white colour.

Matrix: Highly calcareous matrix. 97\%. Colour caries across the photomicrograph from mid redbrown through to pale yellow brown. Very minor optical activity.

Voids: $1 \%$. Meso-macro vughs.

Comments: Characterised by a relative absence of mineral inclusions. The fabric closely resembles the Petrographic Group 5: Vegetal Tempered Fabric.

\section{Geological Sample b}
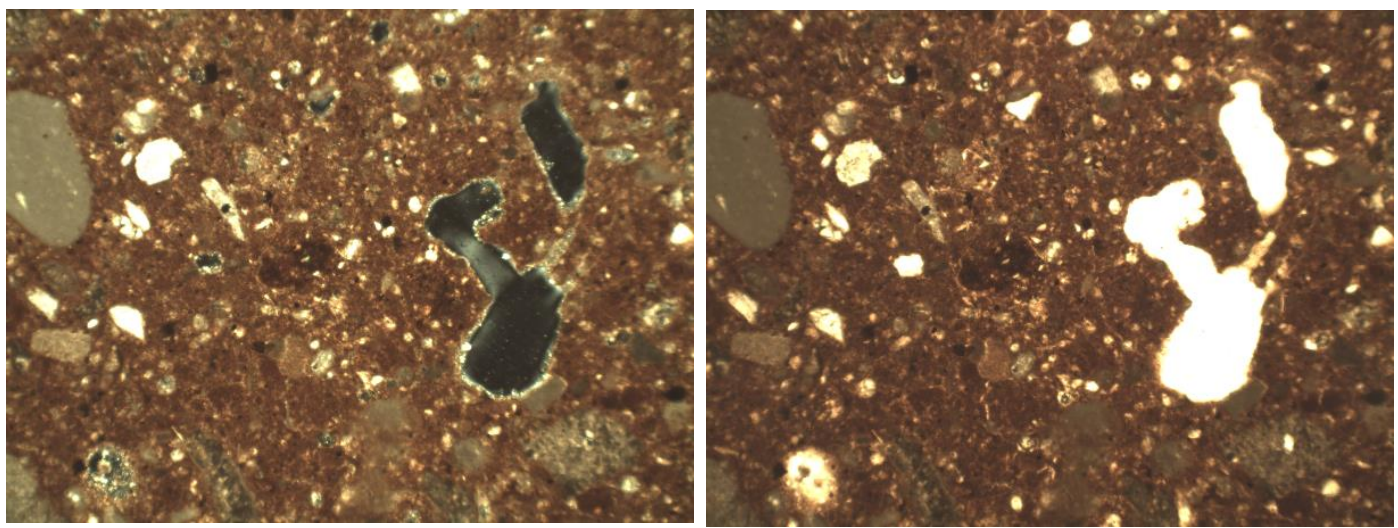

1127

Photomicrograph of Geological Sample b: Left viewed in Crossed Polars (XP) and Right in plane, polarised light (PPL). Image width $3.0 \mathrm{~mm}$

Inclusions: 5\% single spaced. Moderate-weak alignment to margins of sample. Bimodal.

Coarse fraction $(1 \%)$ :

Dominant. Micritic limestone $1 \%$. Equant, sub rounded-rounded $(2.4 \times 1.6 \mathrm{~mm}$ largest, the rest are roughly $0.8 \times 1.2 \mathrm{~mm}$ ). Notable quantities of foraminifera microfossils are noted in the clasts, and all are green-brown in colour. 
Dominant. Micritic Limestone. 0.8x1.6mm. Equant-elongate. Sub angular-sub rounded. Varying proportions of clay to foraminifera microfossils are noted; notable quantities of foraminifera microfossils are noted in some of the clasts, whilst absent from others resulting in differentiating colours ranging from green-brown, dark brown through to opalescent.

Rare. Chert. (0.6x0.6mm). Equant. Sub angular-sub rounded. Black and white colouration.

Rare: Iron-rich mudstone. (0.04x0.08mm) Equant-elongate. Dark red brown-black in XP and PPL. Bedding is noted in PPL.

Very Rare: Calcite. Equant. (0.04x0.06mm) Very angular-angular. High birefringence, pastel colours. Equant-elongate. Very angular. Inclined extinction, multiple twinning and pastel colours in XP. Colourless, low relief in PPL showing clear cleavages at $120^{\circ}$.

Very Rare: Opaque Ironstone/Ferromagnesian Minerals. $(0.02 \times 0.02 \mathrm{~mm})$. Black in PPL, Black in XP. Equant-elongate. Sub rounded-sub angular.

Very rare: Muscovite. $(0.02 \times 0.001 \mathrm{~mm})$ Elongate. Angular. Bright inference colours in XP and clear in PPL.

Matrix: Highly calcareous matrix. 90\%. Mid yellow-brown to red-brown. No core-margin differentiation. No optical activity.

Voids: <2\% Meso vesicles.

Comments: Characterised by the dominance of micritic limestone inclusions with only rare-very rare other mineral inclusions.

\section{Geological Sample c}
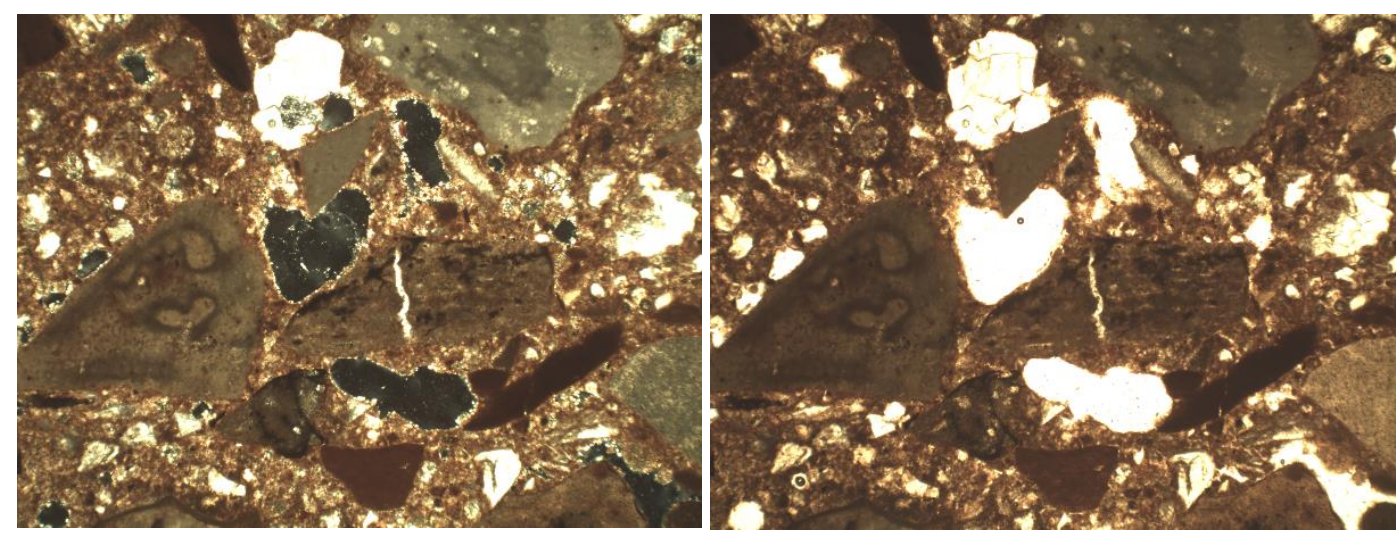

Photomicrograph of Geological Sample c: Left viewed in Crossed Polars (XP) and Right in plane, polarised light (PPL). Image width $3.0 \mathrm{~mm}$

Inclusions: $20 \%$. Close spaced. No alignment to margins of sample. Bimodal.

\section{Coarse fraction $(\mathbf{1 5 \%})$ :}

1165 Dominant. Iron rich mudstone. (0.06x0.08mm) Equant. Dark red brown-black in XP and PPL.

1166 Bedding is noted in PPL.

1167 Very common: Micritic limestone. $(0.8 \mathrm{x} 0.6 \mathrm{~mm})$ Equant-elongate. Varying proportions of clay to

1168 foraminifera microfossils are noted; notable quantities of foraminifera microfossils are noted in some 
of the clasts, whilst absent from others resulting in differentiating colours ranging from green-brown, dark brown through to opalescent.

Common. Calcite. (0.6x0.6mm). Angular. High birefringence, pastel colours. Equant-elongate. Very angular. Inclined extinction, multiple twinning and pastel colours in XP. Colourless, low relief in PPL showing clear cleavages at $120^{\circ}$.

Rare. Chert (1.6x0.8mm). Sub angular. Black and white colouration.

\section{Fine Fraction (5\%):}

Very common: Calcite $(0.4 \mathrm{x} 0.4 \mathrm{~mm})$. Equant. Angular-sub angular. High birefringence, pastel colours. Equant-elongate. Very angular. Inclined extinction, multiple twinning and pastel colours in XP. Colourless, low relief in PPL showing clear cleavages at $120^{\circ}$.

Common: Chert $(0.4 \times 0.3 \mathrm{~mm})$.

Uncommon: Biotite $(0.06 \times 0.02 \mathrm{~mm})$ Elongate. Sub-angular. Brown/yellow in PPL. Pleochroism. Speckled, parallel extinction in XP.

Rare: Radiolarian chert $(0.08 \times 0.08 \mathrm{~mm})$ Equant. Rounded-well rounded.

Rare: Quartz. Equant. (0.3x0.4mm). Angular-sub angular. Undulose extinction.

Matrix: Highly calcareous matrix. 75\%. Mid yellow- orange-brown to red-brown. No core-margin differentiation. Minor optical activity.

Voids: 5\%. Macro-mega vesicles and vughs.

Comments: Large quantity of mineral inclusions, overwhelmingly dominated by micritic limestone, iron-rich mudstone and calcite.

\section{Geological Sample d}
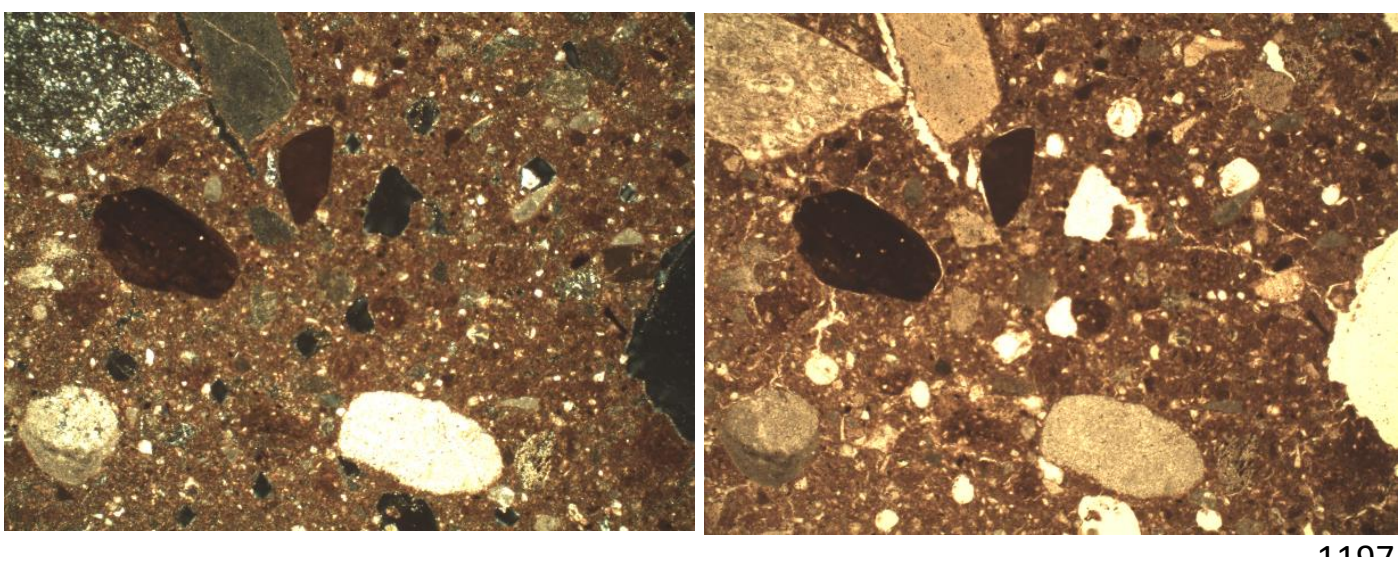

Photomicrograph of Geological Sample d: Left viewed in Crossed Polars (XP) and Right in plane, polarised light (PPL). Image width $3.0 \mathrm{~mm}$

Inclusions: $10 \%$. Single spaced. Slight alignment to margins of sample. Bimodal.

Coarse Fraction (3\%).

Dominant: Micritic Limestone. (1.6x1.0mm) Equant-elongate. Sub angular-sub rounded.

Common: Chert (1.2x0.6mm). Sub angular-sub rounded. Black and white colouration.

\section{Fine Fraction (7\%)}


Dominant: Iron rich mudstone. $(0.5 \times 0.5 \mathrm{~mm})$ Equant-elongate. Dark red brown-black in XP and PPL. Bedding is noted in PPL.

Common. Chert (0.4x0.2mm) Elongate. Sub angular.

Rare. Radiolarian Chert $(0.8 \mathrm{x} 0.8 \mathrm{~mm})$ Equant. Sub angular-sub rounded.

Rare: Biotite. $(0.2 \times 0.1 \mathrm{~mm})$ Elongate. Sub angular. Brown/yellow in PPL. Pleochroism. Speckled, parallel extinction in XP

Rare: Quartz. (0.1x0.1mm). Equant. sub angular-sub rounded.

Very rare: Oolitic limestone/Grainstone. $(0.8 \times 0.4 \mathrm{~mm})$ Elongate. Sub angular. Pale grey in colour. The radial structure of the spherical ooliths are noted along with concentric laminations within the clasts.

Matrix: $88 \%$. Highly calcareous matrix. Mid yellow-brown to red-brown. No core-margin differentiation. Minor optical activity.

Voids: $2 \%$. Meso-macro vesicles and vughs.

Comments: Close match for the oolitic limestone/grainstone noted from the Avroman Formation, near to the location of this geological sample (See Karim 2007: fig 7).

\section{Geological Sample e}
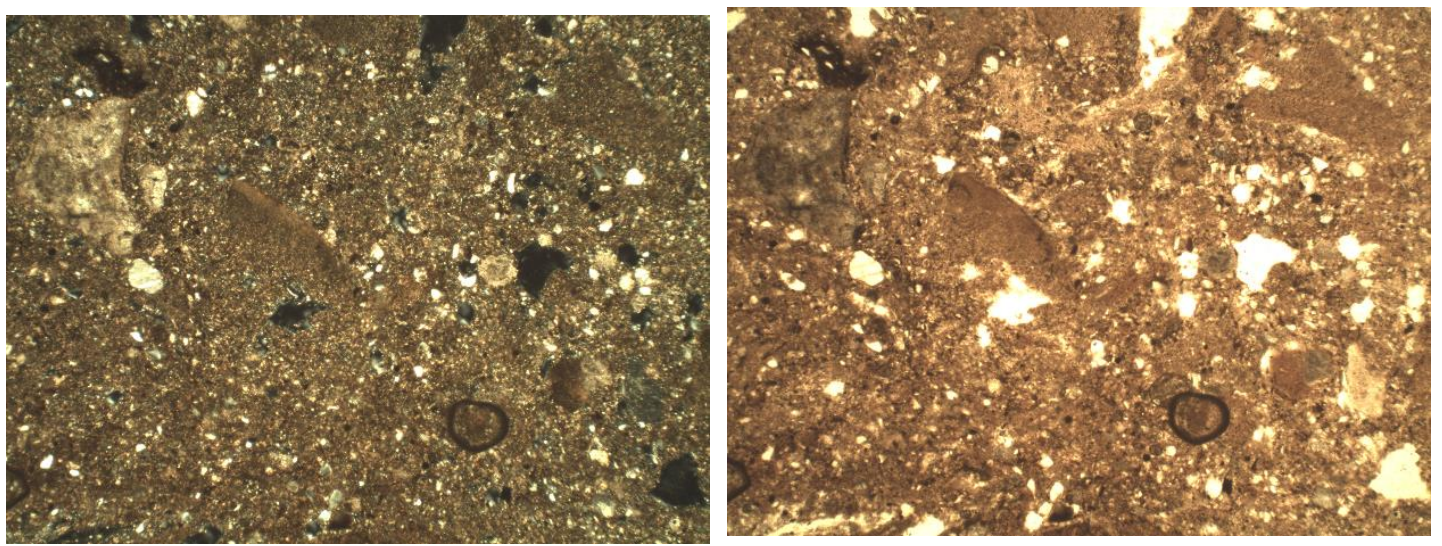

1229

Photomicrograph of Geological Sample e: Left viewed in Crossed Polars (XP) and Right in plane, polarised light (PPL). Image width $3.0 \mathrm{~mm}$

Inclusions: 5\%. Double spaced. No alignment to margins of sample. Unimodal.

1233 Common: Micritic limestone $(0.3 \times 0.3 \mathrm{~mm})$. Equant-elongate. Sub rounded. Mid grey brown in colour. 1234 Ni sign of foraminifera in the clasts within the sample. brown-black in XP and PPL. Bedding is noted in PPL. 
Common: Calcite. $(0.1 \mathrm{x} 0.1 \mathrm{~mm})$. Equant-elongate. Sub rounded-rounded. High birefringence, pastel colours. Equant-elongate. Very angular. Inclined extinction, multiple twinning and pastel colours in XP. Colourless, low relief in PPL showing clear cleavages at $120^{\circ}$.

Rare: Chert. (0.2x0.2mm) Equant. Sub rounded. Black and white coloration.

Rare: Quartz. (0.08mmx0.08mm). Equant. Angular-sub angular. White colour. Undulose extinction.

Rare: Muscovite $(0.08 \times 0.01 \mathrm{~mm})$ Elongate. Angular. Bright inference colours in XP and clear in PPL.

Rare: Oolitic limestone/grainstone $(0.4 \mathrm{x} 0.4 \mathrm{~mm})$ Equant. Sub rounded. Pale grey in colour. The radial structure of the spherical ooliths are noted along with concentric laminations within the clasts.

Matrix: Highly calcareous matrix. 90\%. Mid red-brown exterior with darker brown core. Slight coremargin differentiation. Minor optical activity.

Voids: $<5 \%$. Meso-macro vesicles and vughs.

\section{Geological Sample f}
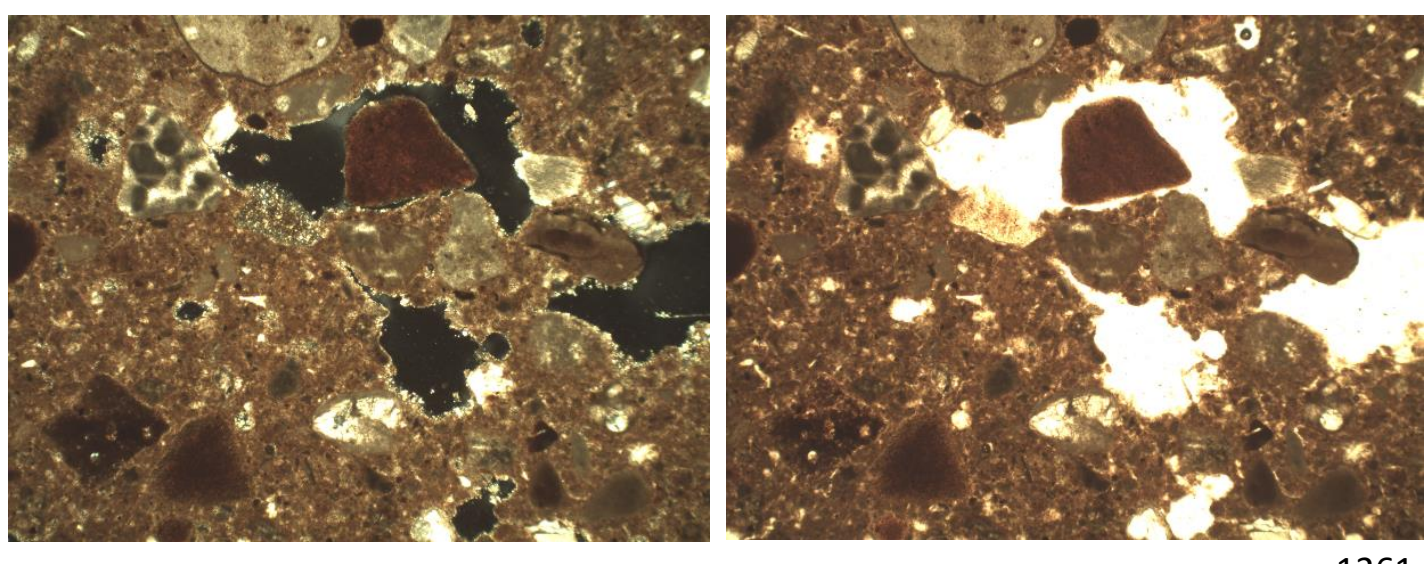

Photomicrograph of Geological Sample f: Left viewed in Crossed Polars (XP) and Right in plane, polarised light (PPL). Image width $3.0 \mathrm{~mm}$

Inclusions: $15 \%$. Single spaced. No alignment to margins of sample noted. Bimodal

\section{Coarse Fraction (10\%).}

Dominant/Abundant. Micritic Limestone. (1.2x1.2mm) Equant-elongate. Varying proportions of clay to foraminifera microfossils are noted; notable quantities of foraminifera microfossils are noted in some of the clasts, whilst absent from others resulting in differentiating colours ranging from greenbrown, dark brown through to opalescent. 
Abundant. Iron rich mudstone (mostly $0.6 \mathrm{x} 0.6 \mathrm{~mm}$ though one huge clast $2.4 \times 2.4 \mathrm{~mm}$ noted). Dark red brown-black in XP and PPL. Bedding is noted in PPL.

Common: Chert. $(0.4 \mathrm{x} 0.8 \mathrm{~mm})$. Most black and white, though some is red/red brown indicating higher iron content in the clasts.

Common: Radiolarian chert. (0.6x0.6mm). Equant-elongate. Sub rounded-rounded.

Rare: Calcite $(0.5 \times 0.4 \mathrm{~mm})$. Equant. Angular to sub-angular. High birefringence, pastel colours. Equant-elongate. Very angular. Inclined extinction, multiple twinning and pastel colours in XP. Colourless, low relief in PPL showing clear cleavages at $120^{\circ}$.

Very rare: Polycrystalline quartz $(0.4 \mathrm{x} 0.4 \mathrm{~mm})$ Equant. Rounded.

Fine Fraction (5\%).

Dominant: Micritic Limestone $(0.2 \times 0.2 \mathrm{~mm})$. Equant. Varying proportions of clay to foraminifera microfossils are noted; notable quantities of foraminifera microfossils are noted in some of the clasts, whilst absent from others resulting in differentiating colours ranging from green-brown, dark brown through to opalescent.

Common: Radiolarian chert. (0.2x0.2mm). Equant-elongate. Sub rounded-rounded.

Common. Calcite. $(0.1 \mathrm{x} 0.1 \mathrm{~mm})$. Equant. Sub angular-sub rounded. High birefringence, pastel colours. Equant-elongate. Very angular. Inclined extinction, multiple twinning and pastel colours in XP.

Colourless, low relief in PPL showing clear cleavages at $120^{\circ}$.

Rare: Quartz (0.08x0.08mm). Equant. Sub angular-angular. White colour. Undulose extinction.

Very rare: Muscovite $(0.1 \times 0.01 \mathrm{~mm})$. Elongate. Angular. Bright inference colours in XP and clear in PPL.

Very rare: Biotite $(0.1 \mathrm{x} 0.01 \mathrm{~mm})$. Elongate. Angular. Brown/yellow in PPL. Pleochroism. Speckled, parallel extinction in XP

Matrix: $80 \%$. Highly calcareous matrix. Pale red-brown. No core-margin differentiation. Very minor optical activity.

Voids: Meso-macro-mega vughs. Meso-macro vesicles.

\section{Geological Sample g}
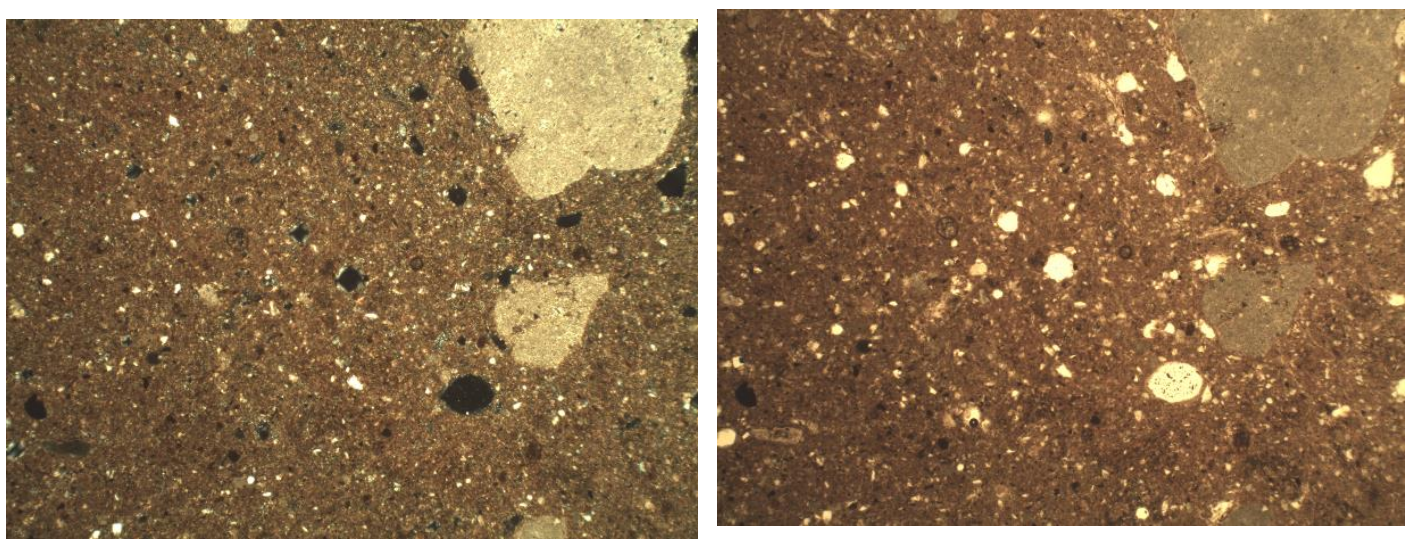
Photomicrograph of Geological Sample g: Left viewed in Crossed Polars (XP) and Right in plane, polarised light (PPL). Image width $3.0 \mathrm{~mm}$

1306 Inclusions: 2\%. Open spaced. No alignment to margins of samples. Unimodal.

1307 Common: Micritic limestone. (Mostly $0.5 \times 0.5 \mathrm{~mm}$, though one much larger clast noted 2.0x2.0mm).

1308

1309

1310

1311

1312

1313

1314

1315

1316

1317

1318

1319

1320

1321

1322

1323

1324

1325

1326

1327

1328

1329

1330

1331

1332

1333 Equant. Sub angular-sub rounded. Varying proportions of clay to foraminifera microfossils are noted; notable quantities of foraminifera microfossils are noted in some of the clasts, whilst absent from others resulting in differentiating colours ranging from green-brown, dark brown through to opalescent.

Rare: Quartz. (0.08x0.08mm). Equant-elongate. Sub angular- angular. White colour. Undulose extinction.

Rare: Chert. (0.16x0.1 mm). Elongate. Sub angular-sub rounded. Black and white colour.

Rare: Iron rich mudstone. $(0.1 \times 0.2 \mathrm{~mm})$ Dark red brown-black in XP and PPL. Bedding is noted in PPL.

Rare: Muscovite $(0.1 \mathrm{x} 0.02 \mathrm{~mm})$ Elongate. Angular. Bright inference colours in XP and clear in PPL.

Matrix: 95\%. Highly calcareous matric. Pale red- brown. No core-margin differentiation. Very minor optical activity.

Voids: $2 \%$. Meso-micro vesicles.

Comments: Very few inclusions. Closely similar with Geological Sample 1 and the Vegetal Tempered Petrographic Fabric.

(1)

